\title{
Blocking Lymphocyte Trafficking with FTY720 Prevents Inflammation-Sensitized Hypoxic-Ischemic Brain Injury in Newborns
}

\author{
Dianer Yang, ${ }^{1,2 *}$ Yu-Yo Sun, ${ }^{1,2 *}$ Siddhartha Kumar Bhaumik, ${ }^{1 \star}$ Yikun Li, ${ }^{1,2}$ Jessica M. Baumann, ${ }^{1,2}$ Xiaoyi Lin, ${ }^{1,2}$ \\ Yujin Zhang, ${ }^{3}$ Shang-Hsuan Lin, ${ }^{4}$ R. Scott Dunn, ${ }^{5}$ Chia-Yang Liu, ${ }^{3}$ Feng-Shiun Shie, ${ }^{8}$ Yi-Hsuan Lee, ${ }^{4}$ \\ Marsha Wills-Karp, ${ }^{9}$ Claire A. Chougnet, ${ }^{6}$ Suhas G. Kallapur, ${ }^{7}$ Ian P. Lewkowich, ${ }^{6}$ Diana M. Lindquist,${ }^{5}$ \\ Kaja Murali-Krishna, ${ }^{1,10}$ and Chia-Yi Kuan ${ }^{1,2}$ \\ ${ }^{1}$ Department of Pediatrics, Children's Healthcare of Atlanta, Atlanta, Georgia 30303, ${ }^{2}$ Center for Neurodegenerative Disease, Emory University School of \\ Medicine, Atlanta, Georgia 30322, ${ }^{3}$ Department of Ophthalmology, College of Medicine, University of Cincinnati, Cincinnati, Ohio 45267, ${ }^{4}$ Department and \\ Institute of Physiology, National Yang-Ming University, Taipei 112, Taiwan, ${ }^{5}$ Imaging Research Center and Divisions of ${ }^{6}$ Immunobiology and \\ ${ }^{7}$ Neonatology/Pulmonary Biology, Cincinnati's Children's Hospital Medical Center, Cincinnati, Ohio 45229, ${ }^{8}$ Center for Neuropsychiatric Research, National \\ Health Research Institute, Miaoli County 35053, Taiwan, ${ }^{9}$ Department of Environmental Health Sciences, Johns Hopkins Bloomberg School of Public \\ Health, Baltimore, Maryland 21205, and ${ }^{10}$ International Center for Genetic Engineering and Biotechnology (ICGEB)-Emory Vaccine Center, ICGEB, 100067 \\ New Delhi, India
}

Intrauterine infection (chorioamnionitis) aggravates neonatal hypoxic-ischemic $(\mathrm{HI})$ brain injury, but the mechanisms linking systemic inflammation to the CNS damage remain uncertain. Here we report evidence for brain influx of T-helper $17\left(\mathrm{~T}_{\mathrm{H}} 17\right)$-like lymphocytes to coordinate neuroinflammatory responses in lipopolysaccharide (LPS)-sensitized HI injury in neonates. We found that both infants with histological chorioamnionitis and rat pups challenged by LPS/HI have elevated expression of the interleukin-23 (IL-23) receptor, a marker of early $\mathrm{T}_{\mathrm{H}} 17$ lymphocytes, in the peripheral blood mononuclear cells. Post-LPS/HI administration of FTY720 (fingolimod), a sphingosine-1-phosphate receptor agonist that blocks lymphocyte trafficking, mitigated the influx of leukocytes through the choroid plexus and acute induction of nuclear factor- $\kappa \mathrm{B}$ signaling in the brain. Subsequently, the FTY720 treatment led to attenuated bloodbrain barrier damage, fewer cluster of differentiation 4-positive, IL-17A-positive T-cells in the brain, less proinflammatory cytokine, and better preservation of growth and white matter functions. The FTY720 treatment also provided dose-dependent reduction of brain atrophy, rescuing $>90 \%$ of LPS/HI-induced brain tissue loss. Interestingly, FTY720 neither opposed pure-HI brain injury nor directly inhibited microglia in both in vivo and in vitro models, highlighting its unique mechanism against inflammation-sensitized $\mathrm{HI}$ injury. Together, these results suggest that the dual hit of systemic inflammation and neonatal $\mathrm{HI}$ injury triggers early onset of the $\mathrm{T}_{\mathrm{H}} 17 / \mathrm{IL}-17$ mediated immunity, which causes severe brain destruction but responds remarkably to the therapeutic blockade of lymphocyte trafficking.

Key words: adaptive immunity; chorioamnionitis; choroid plexus; Fingolimod; FTY720; Th17

\section{Introduction}

Intrauterine infection (chorioamnionitis) is a high risk factor for cerebral palsy in term and near-term neonates (Wu et al., 2003). The combination of perinatal infection/inflammation and hy-

Received June 24, 2014; revised Oct. 9, 2014; accepted Oct. 27, 2014.

Author contributions:Y.-H.L., M.W.-K., C.A.C., S.G.K., I.P.L., D.M.L., M.-W.K., and C.-Y.K. designed research; D.Y., Y.-Y.S., S.K.B., Y.L., J.M.B., X.L., Y.Z., S.-H.L., R.S.D., C.-Y.L., I.P.L., and D.M.L. performed research; F.-S.S., C.A.C., and S.G.K. contributed unpublished reagents/analytic tools; D.Y., Y.-Y.S., S.K.B., Y.L., J.M.B., X.L., Y.Z., S.-H.L., R.S.D., C.-Y.L., Y.-H.L., M.W.-K., I.P.L., D.M.L., and M.-W.K. analyzed data; Y.-Y.S. and C.-Y.K. wrote the paper.

This study was supported in part by National Institutes of Health Grant NS074559 and a Children's Healthcare of Atlanta Trustee grant (C.-Y.K.). We thank Dr. Allan Jobe for providing preterm neonate cord blood samples and Casey Wells for isolation and freezing of mononuclear cells.

*D.Y., Y.-Y.S., and S.K.B. contributed equally to this study.

Correspondence should be addressed to Dr. Chia-Yi Kuan, Health Science Research Building E470, 1760 Haygood Drive, Atlanta, GA 30322. E-mail: alex.kuan@emory.edu.

DOI:10.1523/JNEUROSCI.2582-14.2014

Copyright $\odot 2014$ the authors $\quad 0270-6474 / 14 / 3416467-15 \$ 15.00 / 0$ poxic-ischemic (HI) insult also causes greater brain injury and poorer response to therapeutic hypothermia (Wintermark et al., 2010; Hagberg et al., 2012; Osredkar et al., 2014). The true incidence of chorioamnionitis, ranging from 3 to $30 \%$ in a metaanalysis $(\mathrm{Wu}, 2002)$, is unclear because of heterogeneity in the criteria for clinical diagnosis. These concerns highlight the need for better understanding and more effective therapy of infectionsensitized HI injury in newborns.

In addition, it remains a puzzle how remote maternal infection aggravates neonatal HI brain injury (Leviton et al., 2005), because newborns were often considered immunodeficient, lacking the adaptive immunity to initiate systemic anti-pathogen responses. However, it has been reported that chorioamnionitis induces circulating $\mathrm{CD} 45 \mathrm{RO}$-positive $\left(\mathrm{CD} 45 \mathrm{RO}^{+}\right)$effector/ memory T-cells associated with brain damage in preterm neonates (Duggan et al., 2001). Because the traditional T-helper 1 
A

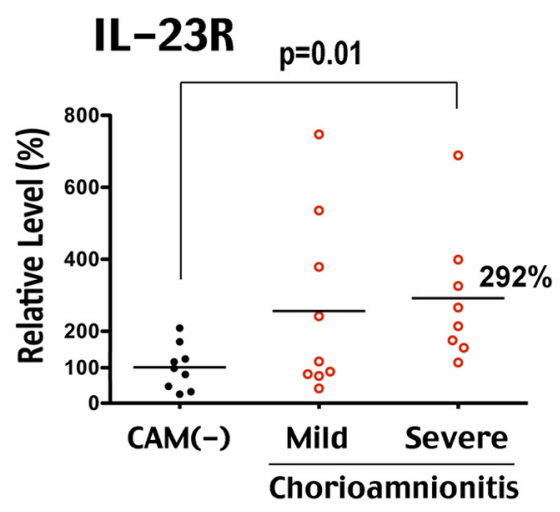

C
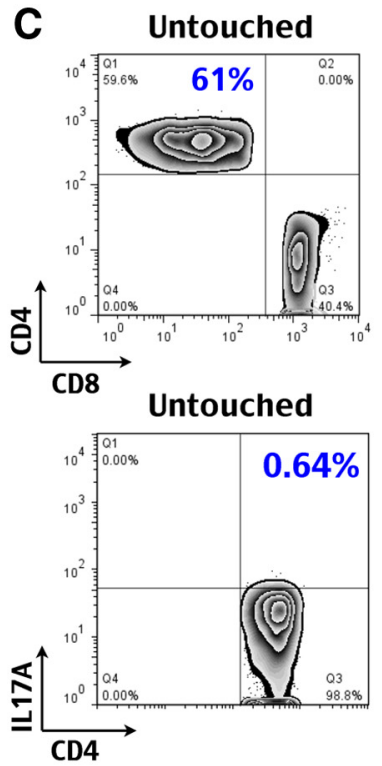

B

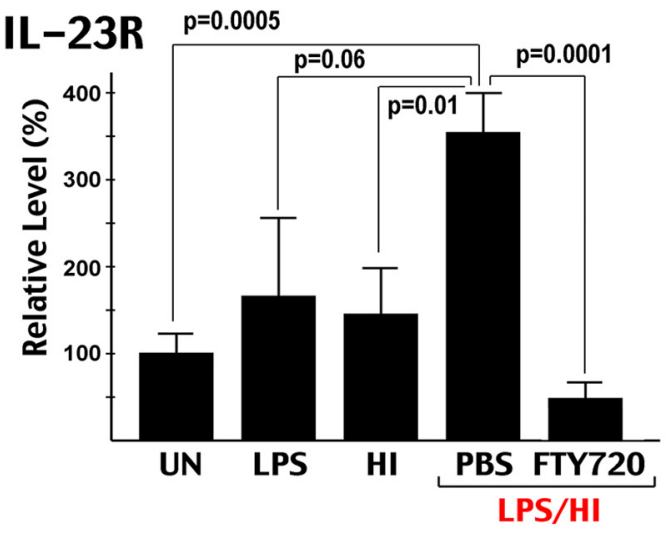

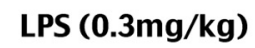

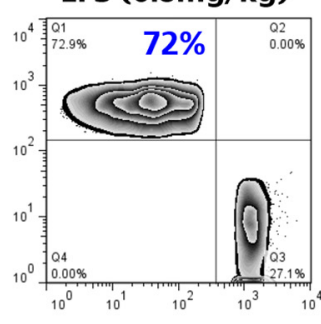

LPS (0.3mg/kg)

Hypoxia-Ischemia

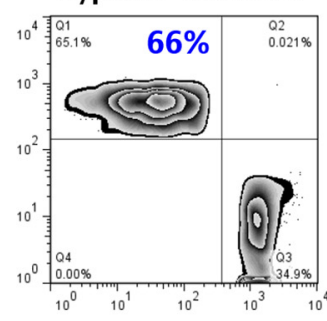

Hypoxia-Ischemia
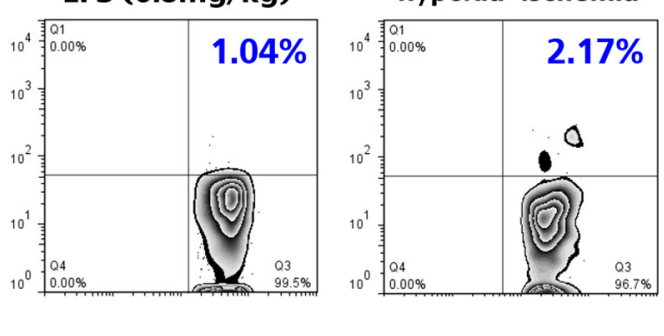

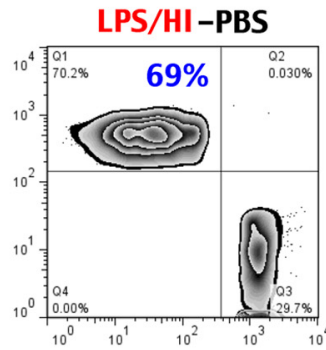

LPS/HI-FTY720
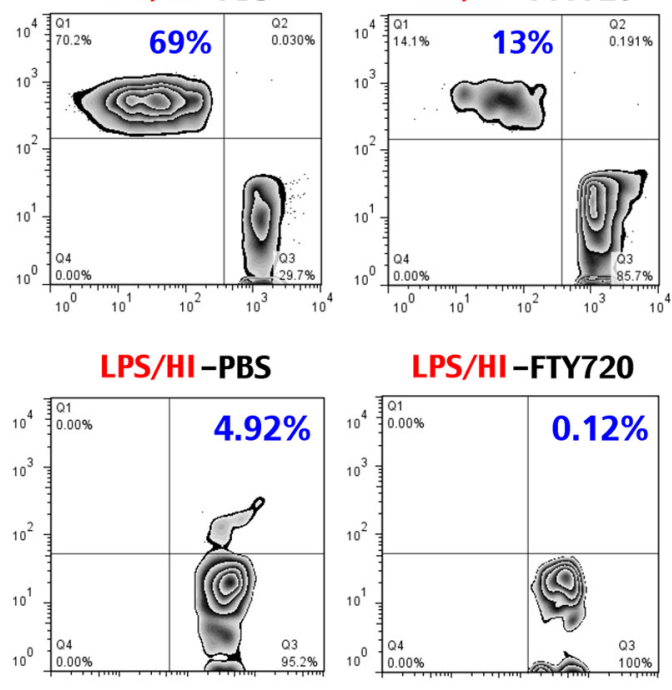

D
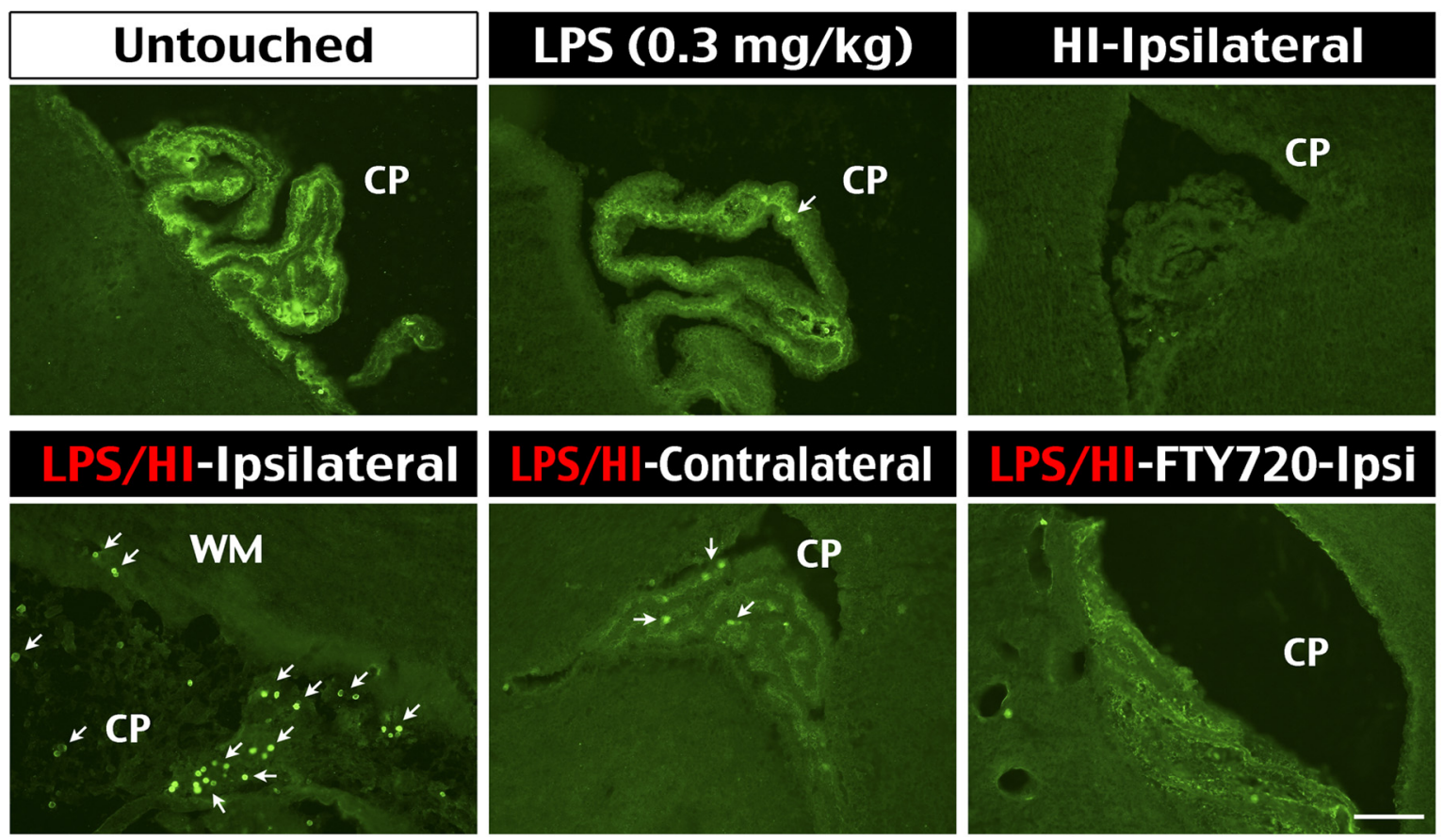

Figure 1. Combined infection-HI induces early-stage $\mathrm{T}_{H} 17$ cells in the blood and infiltration of CD43 ${ }^{+}$leukocytes in choroid plexus. $\boldsymbol{A}$, The CBMCs of preterm neonates, with and without histological chorioamnionitis (CAM) $(n=8-9$ for each group), were compared for the mRNA levels of $I L-23 R$ (normalized to CD3). Mononuclear cells in preterm neonates with severe chorioamnionitis had significant increase $(p<0.05)$ of $/ L-23 R$ transcripts. $B$, The PBMCs of 7-d-old rat pups at $4 \mathrm{~h}$ after $0.3 \mathrm{mg} / \mathrm{kg}$ LPS challenge $(n=5)$, pure-Hl insult $(n=6)$, and (Figure legend continues.) 
$\left(\mathrm{T}_{\mathrm{H}} 1\right)$ or $\mathrm{T}_{\mathrm{H}} 2$ cells are yet to mature in neonates (Sharma et al., 2012), we hypothesized that the early-onset active T-cells after infection/HI injury may be $\mathrm{T}_{\mathrm{H}} 17$-like lymphocytes that have a high propensity to induce autoimmune and inflammatory disorders (Korn et al., 2009). This hypothesis is in accord with recent findings in rhesus macaques showing that experimental chorioamnionitis alters the regulatory T-cell/L-17 balance (Kallapur et al., 2013). Furthermore, several critical factors for $T_{H} 17$-lymphocyte differentiation, including interleukin-6 (IL-6) and IL-1 $\beta$, are induced by neonatal HI injury (Bettelli et al., 2006; Ghoreschi et al., 2010). If this hypothesis is accurate, inflammation-sensitized neonatal HI brain injury may be treated by systemic administration of FTY720 (fingolimod), a sphingosine-1-phosphate receptor (S1PR) agonist that prevents lymphocytes from exiting the lymph nodes and reaching the target organs (Brinkmann et al., 2010).

To test this hypothesis, we compared the expression of $\mathrm{T}_{\mathrm{H}} 17$ lymphocyte markers in cord blood mononuclear cells (CBMCs) among late-preterm neonates with and without chorioamnionitis. We then tested the effects of FTY720 in a lipopolysaccharide (LPS)-sensitized HI brain injury model, in which rodent neonates were exposed to low-dose LPS to mimic subclinical infection and convert a moderate or subthreshold $\mathrm{HI}$ insult to severe brain damage in a Toll-like receptor- 4 and myeloid differentiation primary response gene 88 (MyD88)-dependent manner (Lehnardt et al., 2003; Eklind et al., 2005; Wang et al., 2009). The dual LPS/HI insult also accelerates microglial activation and the brain nuclear factor- $\kappa \mathrm{B}(\mathrm{NF}-\kappa \mathrm{B})$ signaling (Yang et al., 2013a,b), making it a unique paradigm to investigate the mechanisms that connectin systemic inflammatory responses to HI brain injury.

Our experiments showed that the dual hit of systemic LPS exposure and HI triggers early influx of leukocytes and severe brain damage in rodent neonates. However, systemic administration of FTY720 markedly attenuated the LPS/HI-induced brain damage and neuroinflammation, despite its inability to block pure-HI insult or directly inhibit microglial activation. These results suggest unique pathological mechanisms and a novel therapy of inflammation-sensitized HI brain injury in newborns.

\section{Materials and Methods}

LPS/HI surgery and drug treatment. The experimental paradigm of LPSsensitized HI was performed as described previously (Eklind et al., 2005; Wang et al., 2009; Yang et al., 2013a,b). Briefly, LPS $(0.3 \mathrm{mg} / \mathrm{kg}$ body weight) was injected intraperitoneally to 7 -d-old Wistar rat pups $4 \mathrm{~h}$ before the induction of the Vannucci HI procedure. Low-dose LPS was used to mimic subclinical infection, which by itself caused no apparent

$\leftarrow$

(Figure legend continued.) the combined LPS/HI insult with saline (PBS, $n=6$ ) or FTY720 treatment $(n=7)$ were collected to compare the IL-23R mRNA levels (normalized to actin). LPS/HI injury significantly increased the expression of $I L-23 R$ mRNA, which was blocked by the FTY720 treatment. UN, Untouched. C, Flow cytometry showed preferential reduction of CD4 ${ }^{+}$ T-cells in PBMCs by the FTY720 treatment at $16 \mathrm{~h}$ recovery $(13 \%, n=5)$ when compared with untouched $(61 \%, n=3)$, low-dose LPS exposed $(72 \%, n=3)$, pure-Hl injured $(66 \%, n=5)$, or LPS/HI-injured $(69 \%, n=5)$ siblings. Flow cytometry also showed a small increase of CD4 ${ }^{+}$ IL-17A ${ }^{+}$T-cells after pure-HI (2.17\%) and LPS/HI (4.92\%) injury when compared with untouched $(0.64 \%)$, low-dose LPS-exposed (1.04\%), and LPS/HI-challenged but receiving the FTY720 treatment $(0.12 \%)$ rat pups. $\boldsymbol{D}$, Immunostaining showed intense ribbon-like anti-CD43 (leukosialin, W3/13) reactivity in the choroid plexus (CP) of unchallenged $\mathrm{P7}$ rat pups, which was reduced at $4 \mathrm{~h}$ after LPS exposure $(0.3 \mathrm{mg} / \mathrm{kg})$, and in the contralateral hemisphere after LPS/HI insult. In contrast, the ribbon-like CD43 immunoreactivity was greatly reduced in the ipsilateral choroid plexus at $4 \mathrm{~h}$ after pure-HI or LPS/HI insult. CD43 ${ }^{+}$cells (arrows) scattered to the nearby subcortical WM were also detected in the ipsilateral LPS/HI-injured choroid plexus. The reduction of ribbon-like CD43 immunoreactivity in the LPS/HI-injured plexus was less pronounced after the FTY720 treatment ( $n=5$ for each condition). Scale bar, $30 \mu \mathrm{m}$. brain damage but converted a moderate or subthreshold $\mathrm{HI}$ insult to severe brain damage (Eklind et al., 2005; Yang et al., 2013b). Rat pups were anesthetized by $3 \%$ isoflurane mixed with room air when the right common carotid artery was ligated. After $1 \mathrm{~h}$ recovery, pups were placed in glass chambers infused with $10 \%$ oxygen $/ 90 \%$ nitrogen gas and submerged in a $37^{\circ} \mathrm{C}$ water bath. For pure-HI injury, a longer duration of hypoxic challenge ( $90 \mathrm{~min}$ ) was used to produce degrees of brain atrophy similar to those incurred by LPS plus $80 \mathrm{~min} \mathrm{HI}$. After hypoxia, two doses of FTY720 (0.3 or $1 \mu \mathrm{g} / \mathrm{g}$, i.p.; fingolimond hydrochlorides, catalog \#F4633; LC Laboratories) were injected to rats within $30 \mathrm{~min}$ and at $16 \mathrm{~h}$ recovery. Pups of both sexes were used in this study, which showed no discernible difference in responses in pilot study. Animals were randomized for treatments, and the person quantifying brain atrophy were blinded to the treatments. The experimental procedures were approved by the Institutional Animal Care and Use Committee and conformed to the National Institutes of Health (NIH) Guide for Care and Use of Laboratory Animals.

Human subjects. The placenta and umbilical cord blood of late preterm neonates were collected in an NIH-sponsored study (Grants HL97064 and HD57869 to Alan Jobe and S.G.K., both at Cincinnati Children's Hospital Medical Center, Cincinnati, $\mathrm{OH}$ ) approved by the Institutional Review Boards of the Cincinnati Children's Hospital Medical Center and Good Samaritan Hospital (Cincinnati, OH). The inclusion criterion is births between 32.0 and 36.6 weeks gestation by best obstetrical estimate. The exclusion criteria includes the following: (1) infants diagnosed with congenital malformations either prenatally or immediately after birth; (2) infants with an acute life-threatening illness or requiring extensive resuscitation; (3) parents refuse consent or unable to give consent; (4) infants whose mothers have known HIV infection; or (5) infants with diagnosed congenital infection, such as syphilis, cytomegalovirus, toxoplasma, or rubella. The CBMCs were isolated and frozen in aliquots. Chorioamnionitis was diagnosed based on histological evidence of neutrophil infiltration in the fetal membranes or the umbilical cord based on Redline's grading (the magnitude of neutrophil infiltration) and staging (infiltration beyond the anatomic plane of the chorion connective tissue). Umbilical cord inflammation (funisitis) was classified as severe inflammation. Aliquots of CBMCs from normal $(n=8)$, mild $(n=9)$, and severe $(n=9)$ chorioamnionitis groups were selected randomly and thawed for RT-qPCR analysis in the present study.

Intraventricular injection of LPS and transgenic mice. CX3CR1-GFP mice (reported by Jung et al., 2000) were purchased from The Jackson Laboratory (stock \#005582). CCR2-RFP mice (reported by Saederup et al., 2010) were also purchased from The Jackson Laboratory (stock $\# 017586$ ). Intracerebroventricular injection of LPS ( $2 \mu \mathrm{g}$ in P7 rats and 1 $\mu \mathrm{g}$ in $\mathrm{P} 10$ mice) was performed using a stereotaxic apparatus as described previously (Yang et al., 2013a). Briefly, a $10 \mu$ l Hamilton syringe was inserted into lateral ventricle in $\mathrm{P} 7$ rats with the following coordinates: $2.0 \mathrm{~mm}$ rostral and $1.5 \mathrm{~mm}$ lateral to the lambda point at a depth of 2.0 $\mathrm{mm}$ from the surface. For intracerebroventricular injection in P10 mice, the coordinates are $1.0 \mathrm{~mm}$ rostral and $1.0 \mathrm{~mm}$ lateral to the lambda point at a depth of $1.0 \mathrm{~mm}$ from the surface.

Quantitative real-time PCR. For human CBMC samples, total RNA was isolated using the RNeasy micro kit (catalog \#74004; Qiagen) and the high-capacity cDNA reverse transcription kit (catalog \#4366814; Applied Biosystems) following the instructions of the manufacturer. For rat peripheral blood mononuclear cells (PBMCs), the microglia SM826 cells, and neonatal brain tissues, total RNA was isolated using the TRIzol RNA isolation kit (catalog \#15596-026; Invitrogen). Quantitative real-time PCR was performed using a Bio-Rad CFX 96 system (C1000 Thermal Cycler) and detected by SYBR Green master mix (Bio-Rad) as described previous (Yang et al., 2013b). The following primer sequences were used for PCR reaction: $I L-23$ receptor (IL-23R; human), CCAAGCAGCAAACGCACTAG and TCTCAGCCCTGGAAATGACG; CD3e (human), GGCAAGATGGTAATGAAGAAATGA and AGGGCATGTC AATATTACTGTGGTT; $I L-23 a$ (mouse), ACCAGTGGGACAAATG GATCTAC and CAGGTGCTTATAAAACACCAGACC; S1PR1 (rat/ mouse), TGACCTTCCGCAAGAACATCTC and GCACCCCACA TCTAAAAGTAGTAGG; S1PR2 (rat), AAAACCAACCACTGGCTGTC and TGTTCCAGAACCTTCTCAGGA; S1PR3 (rat), GCCCCTA- 

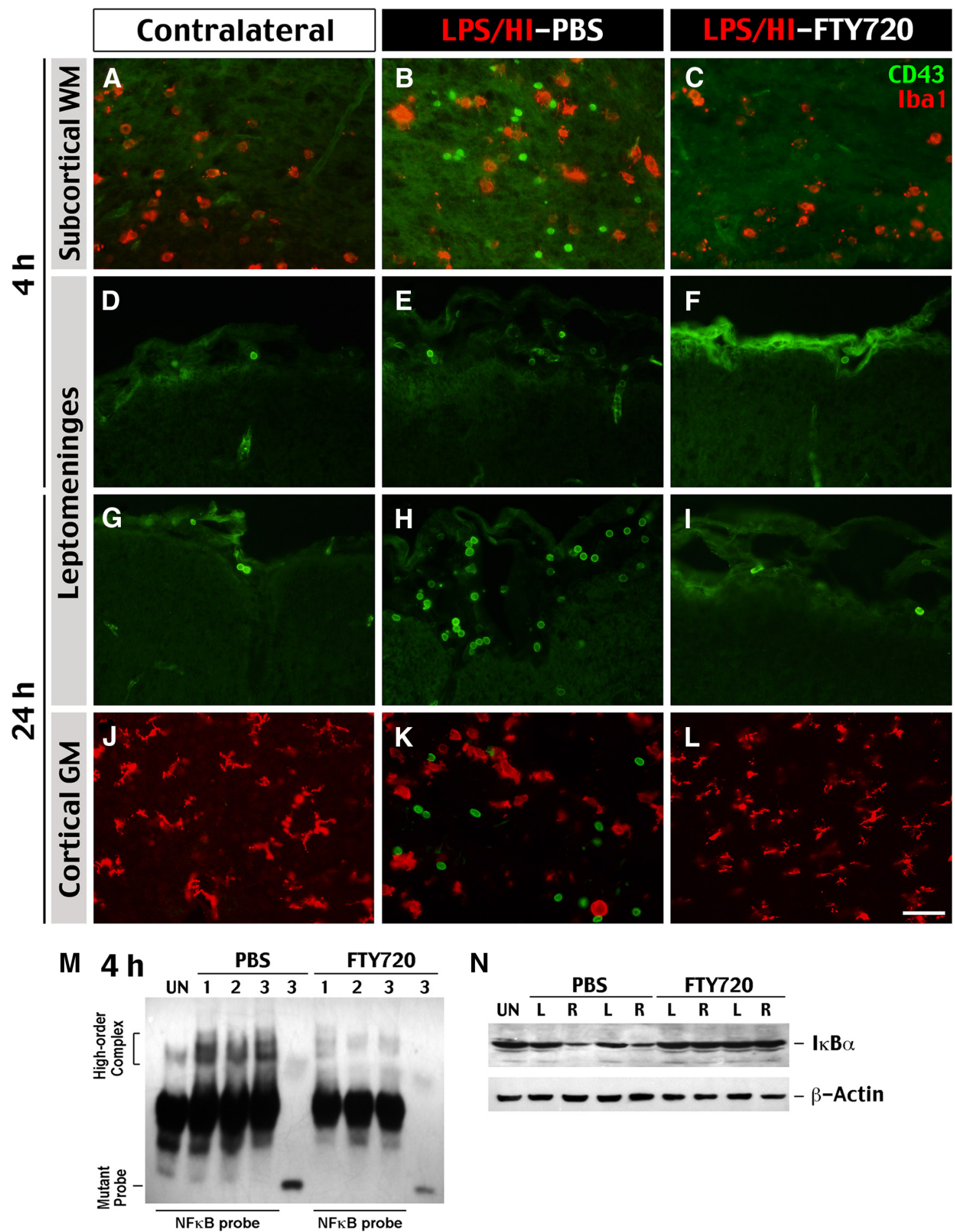

N

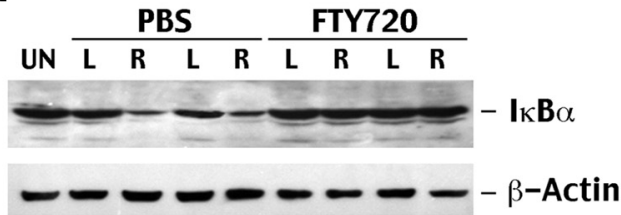

Figure 2. $\quad \mathrm{CD}_{3}{ }^{+}$leukocytes enter neonatal brains after LPS/HI injury in distinct spatiotemporal routes. Immunocytochemistry was used to examine the influx of $\mathrm{CD} 43^{+}$leukocytes and their relationship to lba $1^{+}$microglia/monocytes at 4 and $24 \mathrm{~h}$ after LPS/HI injury and the saline versus FTY720 treatment. $A-C$, At $4 \mathrm{~h}$ after LPS/HI injury, CD43 ${ }^{+}$leukocytes (green) mingled with Iba ${ }^{+}$ameboid microglia/monocytes (red) was detected in the ipsilateral subcortical WM but not in the contralateral hemisphere or after the FTY720 treatment (shown are typical results in $>3$ animals for each). $D-I, C D 43^{+}$leukocytes were only accumulated in the ipsilateral leptomeningeal space of LPS/HI-injured and saline-treated rat pups at $24 \mathrm{~h}$, but not $4 \mathrm{~h}$, recovery. The FTY720 treatment also prevented the accumulation of $C D 43^{+}$leukocytes in the leptomeningeal space. $J-L$, At $24 \mathrm{~h}$ recovery, $C D 43^{+}$leukocytes mingled with round, activated Iba $1^{+}$microglia/monocytes were detected in the ipsilateral cortical gray matter (GM) of LPS/HI-injured rat pups. In contrast, CD43 ${ }^{+}$leukocytes were absent in the contralateral hemisphere or in pups that received FTY720 (shown are typical results in $n>6$ animals). Scale bar, $20 \mu \mathrm{m}$. $M$, The NF- $\kappa$ B EMSA with the rat brain nuclear extract collected at $4 \mathrm{~h}$ recovery from LPS/HI insult and the saline versus FTY720 treatment. The FTY720 treatment prevented the high-order DNA-protein complex using a specific NF- $\kappa B$ probe (shown are the responses of 3 animals for each treatment). Mutant NF- $\kappa$ B probe was used as negative controls. $N$, At the same time, LPS/HI insult caused reduction of the cytoplasmic $1 \kappa B \alpha$ in the ipsilateral hemisphere (asterisks; right, R), which was also averted by the FTY720 treatment (shown are typical results in 2 subjects). L, Left; UN, untouched. 
A
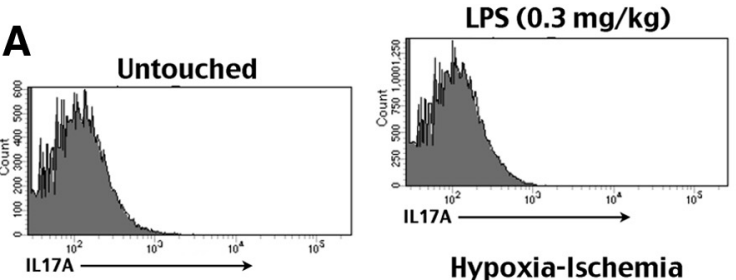

Hypoxia-Ischemia

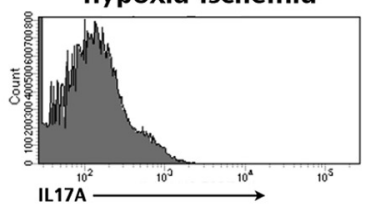

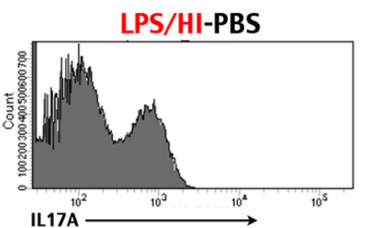

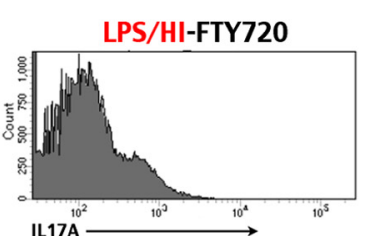

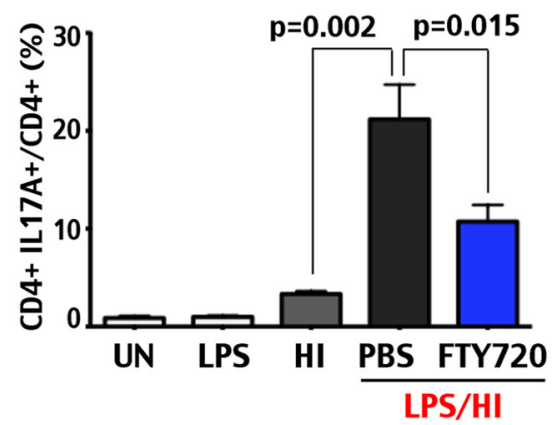

B
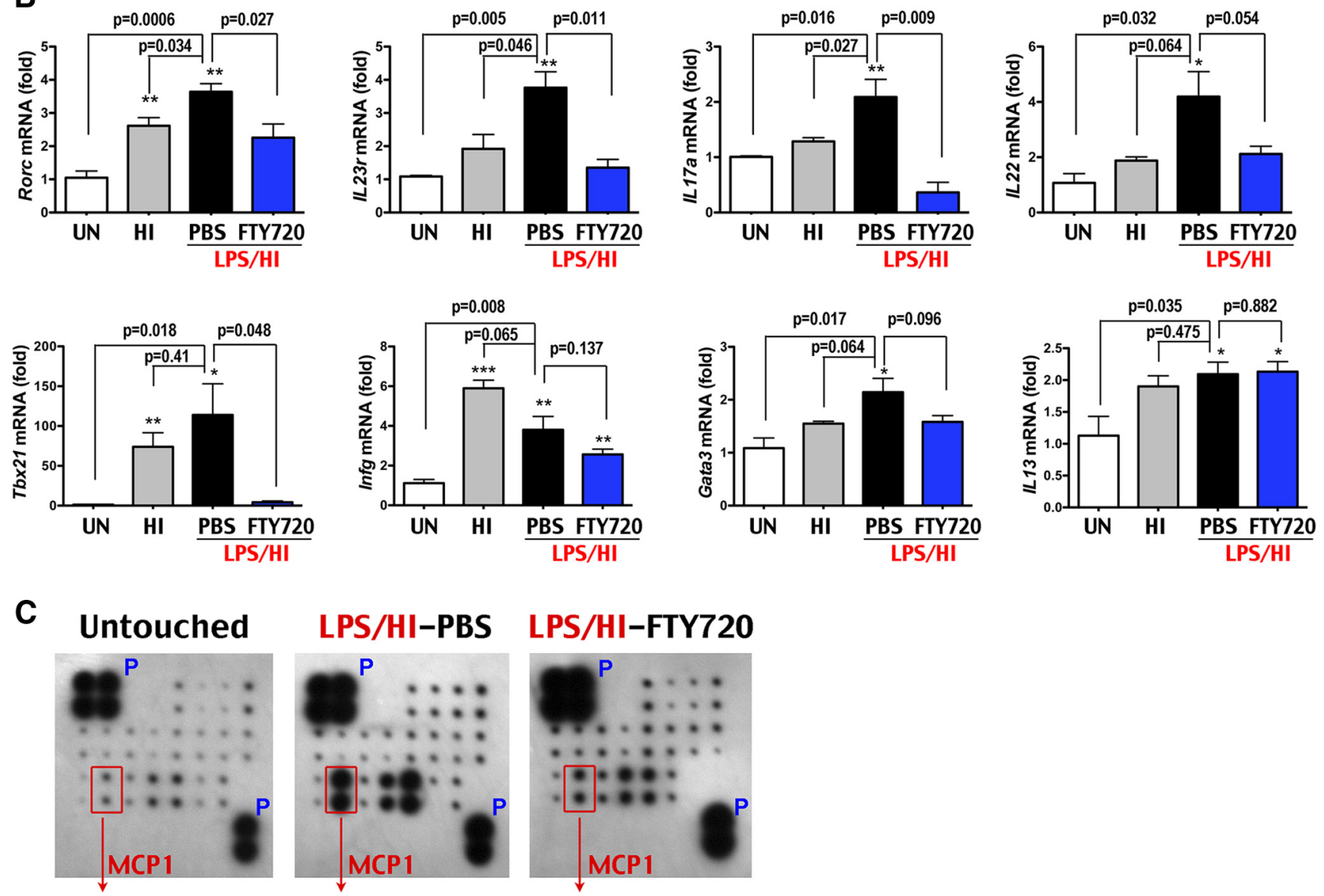
$1.04 \pm 0.03$
$9.7 \pm 0.77$
$3.04 \pm 0.24$

\section{Brain}

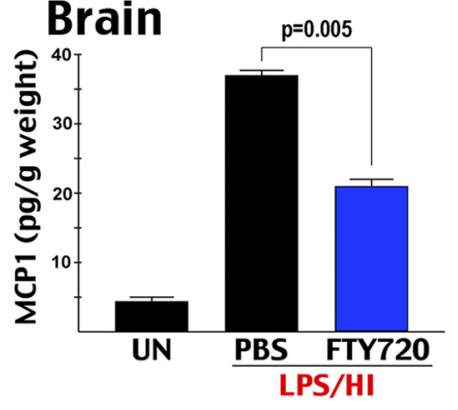

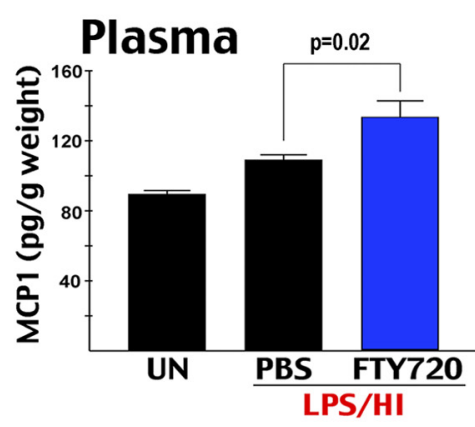

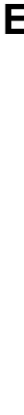

Figure 3. FTY720 prevents LPS/HI-induced accumulation of $\mathrm{CD} 4^{+} \mathrm{IL}-17 \mathrm{~A}^{+}$lymphocytes and neuroinflammation in neonatal brains. $A$, Flow cytometry showed significant increase of $\mathrm{CD} 4{ }^{+}$ $\mathrm{IL}-17 \mathrm{~A}^{+}$cells in the brain of LPS/HI-injured rats $(n=7)$ at $24 \mathrm{~h}$ recovery, which was reduced by the FTY720 treatment $(n=8)$. In contrast, neither untouched (UN; $\left.n=6\right), 0.3 \mathrm{mg} / \mathrm{kg} \mathrm{LPS}$-challenged $(n=4)$, or pure-HI injured $(n=5)$ rats showed $>3 \%$ of $\mathrm{CD}^{+}{ }^{+} \mathrm{IL}-17 \mathrm{~A}^{+}$T-cells among all $\mathrm{CD} 4^{+}$lymphocytes. $\boldsymbol{B}$, The combined LPS/HI injury caused significantly (Figure legend continues.) 
AACTGGAGCCTTA and GCCAGGAACGTTCATTTCAG; S1PR4 (rat), CAAGACCAGCCGTGTGTATG and AAGAGCACATAGCCCTTGGA; S1PR5 (rat), ATCCCTTGGTGCTGAAGTTG and GATGTCGCAGCTGTATCCTG; translocator protein (Tspo; rat), CTATGGTTCCCTTGGGTCTCTAC and AGGCCAGGTAAGGATACAGCAAG; IL-17a (rat), GACTCTGAGCCGCAATGA and ATGTGGTGGTCCAACTTCC; IL-22 (rat), CCTTCCCTCCACTCTATAAGGAA and GGGGCAGAAACCAGTCTTAGTAT; $I L-23 R$ (rat), CAGCTCGAGTTTGGTATAAAGG and GCATGTCATGTTGCCTGAGTAT; interferon- $\gamma$ (IFN $\gamma$; rat), CTGTTACTGCCAAGGCACACT and CTGGCTCTCAAGTATTTTCGTG; $I L-13$ (rat), ACAAGACCAGAAGACTTCCCTGT and CTTTTGGTTACAGAGGCCATTC; inducible nitric oxide synthase (iNOS; mouse), TACCAAAGTGACCTGAAAGAGGA and ATTCTGGAACATTCTGTGCTGTC; tumor necrosis factor- $\alpha$ (TNF $\alpha$; mouse), CCACCACGCTCTTCTGTCTA and CTCCTCCACTTGGTGGTTTG; Tbx21 (mouse), GATGTTTGTGGATGTGGTCTTG and GTGAGCTTTAGCTTCCCAAATG; $\beta$-actin (rat), GGCACCACACTTTCTACAATGA and AGTGGTACGACCAGAGGCATAC; Gapdh (mouse), CTCATGACCACAGTCCATGC and TTCAGCTCTGGGATGACCTT; Gata3 (rat), CTACTACGGAAACTCGGTCAGG and GATGGACGT CTTGGAGAAGG; and RAR-related orphan receptor C (Rorc; rat), CCTTCCCTCCACTCTATAAGGAA and GGGGCAGAAACCAGTCTTAGTAT.

Matrix metalloproteinase zymogram. The matrix metalloproteinase (MMP) zymography was performed as described previously (Yang et al., 2013a). Briefly, $0.15 \%$ porcine skin gelatin was added into the SDS-PAGE gel. Protein samples were extracted and run in the same condition as the standard SDS-PAGE gel. After electrophoresis, gels were washed twice with $2.5 \%$ Triton X-100, incubated in the reaction buffer (in mM: 50 Tris, pH 7.5, $200 \mathrm{NaCl}$, and $5 \mathrm{CaCl}_{2}$ ) at $37^{\circ} \mathrm{C}$ overnight, then stained with $2 \%$ Coomassie blue, and destained for visualization. Shown are color-inverted images of the zymogram gel.

Assessment of blood-brain barrier permeability. The blood-brain barrier (BBB) permeability was determined as described previously (Yang et al., 2013a). Briefly, 5\% sodium fluorescein (NaF) (Sigma-Aldrich) solution was injected intraperitoneally to rat pups at the dose of $10 \mu \mathrm{l} / \mathrm{g}$ body weight. Two hours later, animals were killed by transcardial perfusion of saline to wash out $\mathrm{NaF}$ in the circulation. The brains were then removed and photographed using a fluorescence stereomicroscope. Bilateral cerebral cortexes were separated and homogenized with $500 \mu \mathrm{l}$ of trichloroacetic acid $(80 \%)$ for centrifuge at $13,600 \times g$ for $10 \mathrm{~min}$. Triplicates of $150 \mu \mathrm{l}$ supernatant added with $50 \mu \mathrm{l}$ of $5 \mathrm{M} \mathrm{NaOH}$ were mixed in 96-well microplate and measured by spectrophotometer with the absorption wavelength at $490 \mathrm{~nm}$.

$N F-\kappa B$ electrophoresis mobility shift assay. NF- $\kappa$ B electrophoresis mobility shift assay (EMSA) was performed using the light-shift chemiluminescent kit (catalog \#20148; Thermo Fisher Scientific) as described previously (Yang et al., 2013a,b). Briefly, $5 \mu$ l of nuclear extract from brains, $2 \mu \mathrm{l}$ of binding buffer, $1 \mu \mathrm{l}$ of poly(dIdC), $1 \mu \mathrm{l}$ of biotin-labeled oligonucleotide probe, and $1 \mu \mathrm{l}$ of super-pure water were mixed, spun down to the bottom of the tube, and incubated at room temperature for $30 \mathrm{~min}$. The sample was then loaded to $5 \%$ nondenaturing polyacrylamide gel and run for $2.5 \mathrm{~h}$ in $0.5 \times$ Tris/Borate/EDTA (TBE) buffer. The binding reactions were electrophoretically transferred to nylon mem-

$\leftarrow$

(Figure legend continued.) increased RORC, IL-23R, and IL-17A mRNA, as well as a trend of increase in $/ L-22 \mathrm{mRNA}$ (all $\mathrm{T}_{\mathrm{H}} 17$ markers) than pure-HI injury ( $n=4$ for each). The induction of Tbx21/T-bet (a $\mathrm{T}_{\mathrm{H}} 1$ and mixed $\mathrm{T}_{\mathrm{H}} 1 / \mathrm{T}_{\mathrm{H}} 17$ cell marker), IFN $\gamma$ (a $\mathrm{T}_{\mathrm{H}} 1$ cell marker), or Gata 3 and IL-13 mRNA ( $\mathrm{T}_{\mathrm{H}} 2$ cell markers) was similar between pure-HI and LPS/HI insults. The FTY720 treatment significantly decreased the LPS/HI-induced expression of RORC, IL-23 receptor, IL17A, and Tbx21/T-bet mRNA but not in IFN $\gamma$, Gata3, or IL-13 mRNA $(n=4)$. C, Cytokine array showed a 9.7-fold increase of the brain MCP1 protein at $24 \mathrm{~h}$ after the LPS/HI insult, which was reduced to threefold in FTY720-treated rats ( $n=4$ for each). D, ELISA also showed significant attenuation of the LPS/HI-induced MCP1 expression in the brain, but not the plasma, of FTY720treated animals ( $n=4$ for each). $\boldsymbol{E}$, The FTY720 treatment also markedly reduced the postLPS/HI induction of TSPO (translocation protein of $18 \mathrm{kDa}$, a marker for activated microglia) mRNA ( $n=4$ for each). brane under $300 \mathrm{~mA}$ for $45 \mathrm{~min}$ and UV crosslinked. The positions of biotin-labeled probe were detected using streptavidin-conjugated chemiluminescence and $\mathrm{x}$-ray film. The sequences of oligonucleotide probes containing normal or mutant NF- $\kappa \mathrm{B}$ enhancer-binding sites were identical to those described previously (Yang et al., 2013a,b).

Cytokine array and ELISA. Cytokine array was performed as described previously using the ChemiArray antibody array system (RayBiotech) and following the instructions of the manufacturer (Yang et al., 2013a). For ELISA, rat brain tissue and cells were lysed in TLB buffer $[20 \mathrm{mmol} / \mathrm{L}$ Tris, pH 7.4, $137 \mathrm{mmol} / \mathrm{L} \mathrm{NaCl}, 25 \mathrm{mmol} / \mathrm{L} \beta$-glycerophosphate, 25 $\mathrm{mmol} / \mathrm{L} \mathrm{Na}$-pyrophosphate, $2 \mathrm{mmol} / \mathrm{L}$ EDTA, $1 \mathrm{mmol} / \mathrm{L} \mathrm{Na}_{3} \mathrm{VO}_{4}, 1 \%$ Triton X-100, 10\% glycerol, $1 \mathrm{mmol} / \mathrm{L}$ phenylmethylsulfonyl fluoride, and protease inhibitor cocktail (Sigma)] and then measured using a rat commercial monocyte chemoattractant protein 1 (MCP1) kit (RayBiotech). Mouse IL- $1 \beta$, TNF $\alpha$, and IL- 6 concentrations in the cell lysate were measured using a cross-species reactive antibody $(\mathrm{R} \& \mathrm{D}$ Systems). The results were detected using an ELISA reader at a wavelength of $450 \mathrm{~nm}$.

Behavioral testing. Rats were placed on an elevated rotating rod $(3 \mathrm{~cm}$ in diameter) for four trials per day, during which time the rotating rod underwent acceleration from 4 to $40 \mathrm{rpm}$ over $3 \mathrm{~min}$ and then remained at the maximum speed. Animals were scored for their latency (in miniseconds) to fall in each trial. Animals rested a minimum of $10 \mathrm{~min}$ between trials to avoid fatigue.

Measurement of brain damage. Brain tissue loss was performed at $7 \mathrm{~d}$ after pure-HI or LPS-sensitized HI injury as described previously (Yang et al., 2013a,b). Briefly, pups were killed under deep anesthesia by transcardiac perfusion of saline, and the brains were fixed overnight, followed by serial sectioning of 1-mm-thick slices on a Vibratome (Stoelting). Each section was photographed, and the extent of tissue loss in the cerebral cortex, striatum, and hippocampus was quantified as the area ratio of all sections containing the structure of interest on the lesion to the contralateral hemispheres using the $\mathrm{NIH}$ Image 1.4 software. The persons analyzing brain damage were blinded to the treatment of animals.

Microglia culture and phospho-FTY720 treatment. Immortalized primary mouse microglia in BALB/c background (SM826 cells; developed by F.-S.S. and to be reported elsewhere) were cultured in DMEM (Invitrogen) with $10 \%$ FBS and treaded by $5 \mathrm{ng} / \mathrm{ml}$ LPS (Sigma-Aldrich), with or without 2-10 $\mu \mathrm{M}$ phospho-FTY720 and S1P (Echelon Biosciences), for the mRNA and protein analysis.

Immunoblot analyses. Brain protein extracts were separated by the standard SDS-PAGE procedure, electrotransferred to a microporous polyvinylidene fluoride membrane (Bio-Rad), and detected with designated antibodies using the HRP chemiluminescence reagents (GE Healthcare). The antibodies used were as follows: mouse anti-nuclear factor $\kappa \mathrm{B}$ inhibitor- $\alpha$ ( $\mathrm{I} \kappa \mathrm{B} \alpha$; catalog \#4814; Cell Signaling Technology), rabbit anti-NF- $\kappa$ B p65/RelA (catalog \#4764; Cell Signaling Technology), rabbit anti-Histone $\mathrm{H3}$ (catalog \#9715; Cell Signaling Technology), mouse anti-cyclooxygenase 2 (COX2; catalog \#610204; BD Biosciences), rabbit anti-iNOS (catalog \#610332; BD Biosciences), and mouse anti- $\beta$-actin (catalog \#A5441; Sigma-Aldrich).

Histology. Immunohistochemistry were performed on 20 - $\mu$ m-thick frozen sections as described previously. The following antibodies were used: mouse anti-CD43 (W3/13, catalog \#MCA54G; AbD Serotec) and rabbit anti-ionized calcium-binding adapter molecule 1 (Iba1; catalog \#019-19741; Wako). Secondary antibody was conjugated to Alexa Fluor 488 or Alexa Fluor 594 (Invitrogen).

Brain immune cell isolation and flow cytometry. Infiltrated immune cells in neonatal brains were isolated as described previously (Pino and Cardona, 2011). Briefly, brain tissues were gently homogenized with glass tissue grinder and resuspended in final 30\% Percoll (GE Healthcare). The density gradient was centrifuged at $500 \times g$ for 30 min and then collected the $70-30 \%$ interphase. The suspension was diluted threefold with ice-cold HBSS and centrifuged at $500 \times g$ for 10 min. Resuspended cells were then counted and stained for flow cytometry. The following antibodies were used for FACS: anti-CD4 R-Phycoerythrin (OX38, catalog \#551397; BD Pharmingen) and antiIL-17A Allophycocyanin (catalog \#A14782; Invitrogen). Data were 

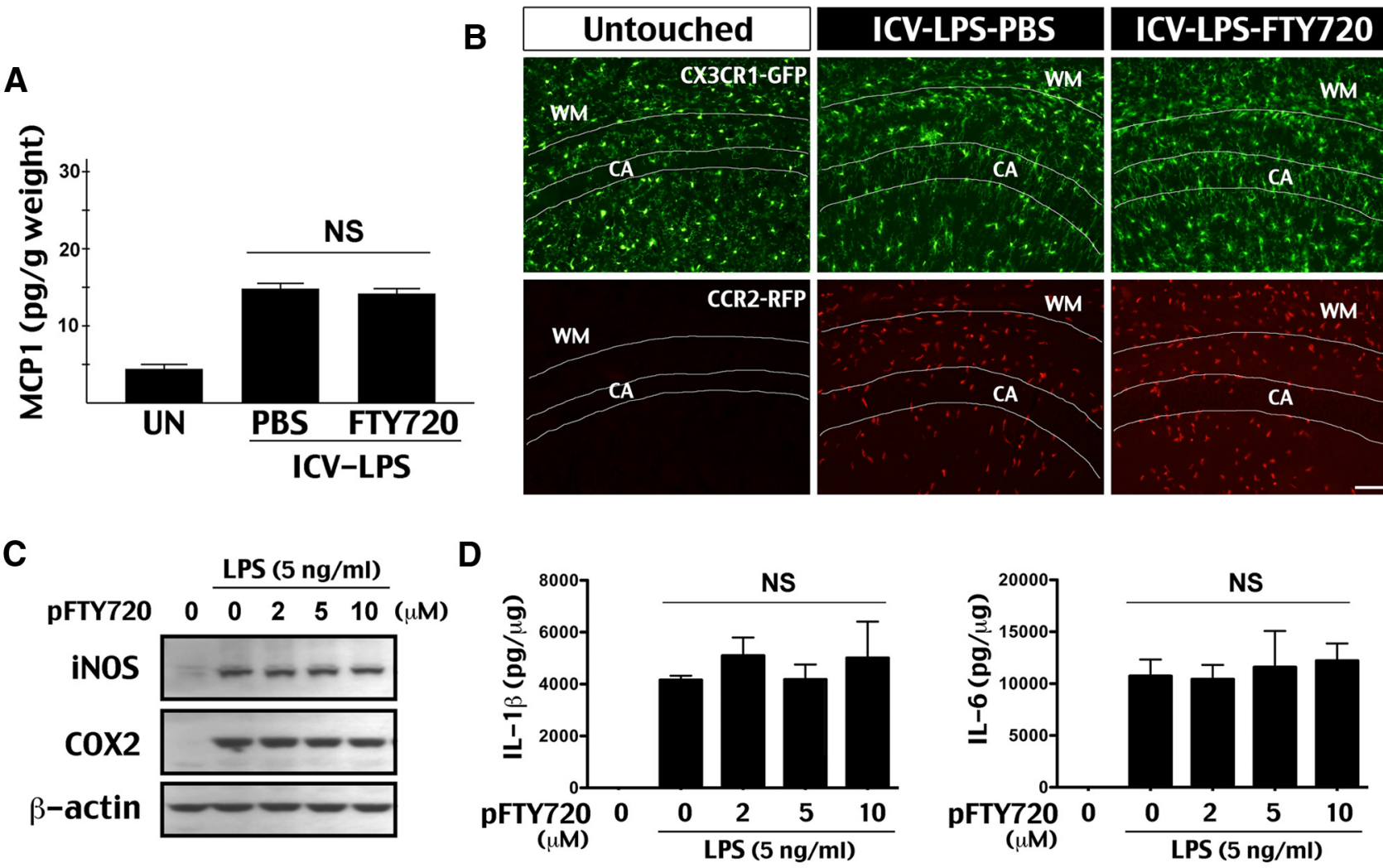

E

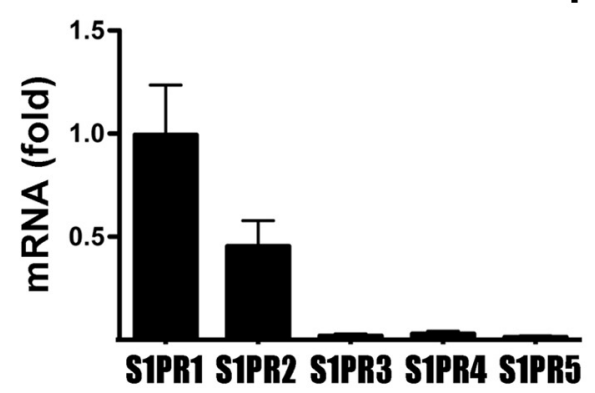

$\mathbf{F}$

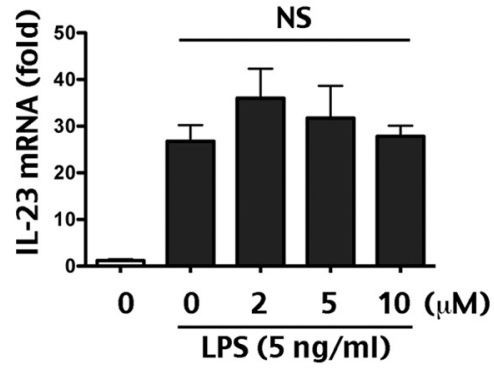

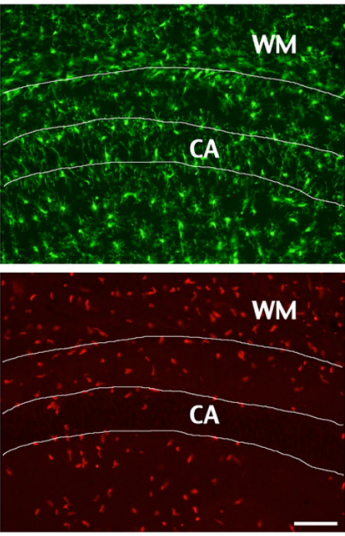

WM

\section{S1P}

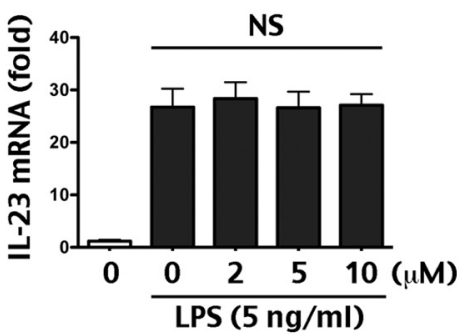

G

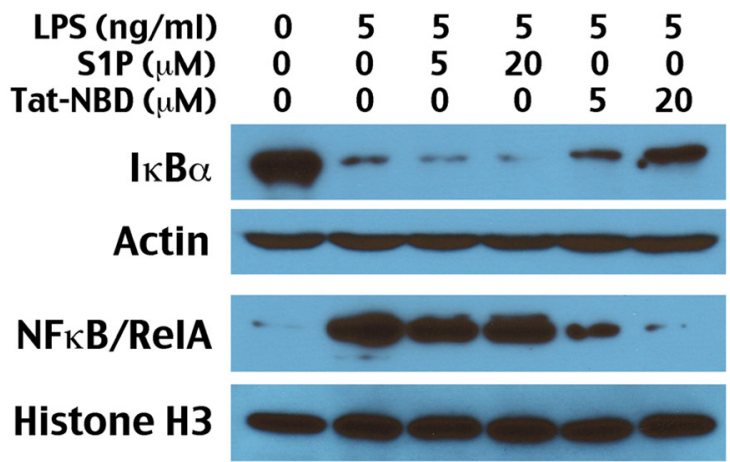

H

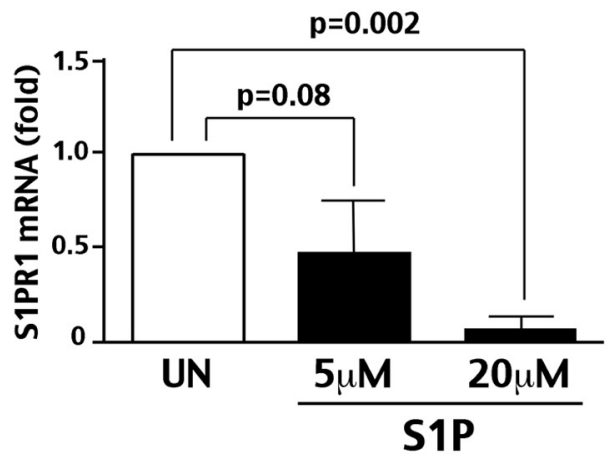

Figure 4. FTY720 exerts no direct inhibition of microglial activation. A, FTY720 (1 $\mu \mathrm{g} / \mathrm{g}$, i.p.) was unable to prevent the induction of MCP1 after intracerebroventricular (ICV) injection of LPS (2 $\mu \mathrm{g}$ ) in P7 rats, a model of direct microglial activation $(n=4$ for each). $\boldsymbol{B}$, Visualization of microglia and monocytes in P10 CX3CR1-GFP; CCR2-RFP mice and $24 \mathrm{~h}$ after intracerebroventricular injection of LPS $(1 \mu \mathrm{g})$ with saline or FTY720 treatment $(1 \mu \mathrm{g} / \mathrm{g})$. In untouched mice, few GFP ${ }^{+}$microglial processes extended into the pyramidal cell layer in the hippocampus (CA) and almost no RFP $^{+}$monocytes were detected in the brain. After intracerebroventricular LPS injection with either saline or FTY720 treatment, hypertrophic microglial processes extended into the pyramidal cell layer and a large number of monocytes were found in the brain ( $n=3$ for each). C, Application of pFTY720 (2-10 $\mu \mathrm{m})$ failed to prevent LPS ( $5 \mathrm{ng} / \mathrm{ml})$-induced iNOS and COX2 expression in immortalized microglia SM826 cells (repeated 3 times). D, Similarly, pFTY720 failed to attenuate the LPS-mediated induction of inflammatory cytokines, including IL-1 $\beta$ and IL-6, in SM826 cells (repeated 3 times). E, RT-qPCR analysis showed high expression of the S1PR1 and S1PR2 isoforms in neonatal rat microglia. A previous study showed that pFTY720 lacks (Figure legend continues.) 
acquired with an LSRII flow cytometer (BD Biosciences) equipped with lasers tuned to $488,561,640,405$, and $355 \mathrm{~nm}$ using digital DiVa Software. Spectral overlap was compensated, and data were analyzed using FlowJo software (Treestar).

Magnetic resonance imaging. All data were collected on a $7 \mathrm{~T}$ magnetic resonance imaging (MRI) system (Bruker BioSpec 70/30) equipped with $400 \mathrm{mT} / \mathrm{m}$ actively shielded gradients, as described previously (Shereen et al., 2011). Animals were anesthetized by $1-2 \%$ isoflurane in air, respiration rate was maintained at $60-100$ breaths/ min, and temperature was maintained at $37^{\circ} \mathrm{C}$ by warm air circulated through the magnet bore. All animals were scanned with a custombuilt radio frequency coil. After the acquisition of anatomical localizer images, two-dimensional diffusion-weighted images were collected using a four-shot diffusion-weighted spin-echo echo planar imaging sequence with 30 directions, a $b$-value of $670 \mathrm{~s} / \mathrm{mm}^{2}$, FOV of $32 \times 32 \mathrm{~mm}^{2}$, TE of $40 \mathrm{~ms}$, TR of $5400 \mathrm{~ms}$, four averages, matrix of $256 \times 256$, and $0.5 \mathrm{~mm}$ slice thickness. The acquisition time was $\sim 50$ min. Analysis was performed using the DTIStudio (www.dtistudio.org) and NIH ImageJ software. Regions of interest were prescribed in the striatum, hippocampus, and rostral and caudal areas of the cortex. Apparent diffusion coefficients (ADCs) were averaged separately for the ipsilateral and contralateral sides at each time point.

Sodium MRI was acquired using a gradient recalled echo sequence with a TE of $1.52 \mathrm{~ms}$, TR of $100 \mathrm{~ms}, 900$ averages, FOV of $48 \times 48 \mathrm{~mm}$, matrix of $32 \times 32$, and slice thickness $4.2 \mathrm{~mm}$. Total scan time for this sequence was $48 \mathrm{~min}$. The signal intensities from regions-of-interest in the ipsilateral and contralateral hemispheres were normalized to the signal intensity of jaw muscle, which was assumed to have a sodium concentration of $45 \mathrm{~mm}$, as described previously (Wetterling et al., 2010), to calculate an estimated tissue sodium content.

Manganese-enhanced MRI (MEMRI) data were acquired using a T1-weighted 3D MSME sequence with an FOV of $32 \times 19.2 \times 19.2$ $\mathrm{mm}$, matrix of $256 \times 96 \times 96$, TE of $10 \mathrm{~ms}$, TR of $200 \mathrm{~ms}$, one average, and total acquisition time of $30 \mathrm{~min} . \mathrm{MnCl}^{2}(125 \mathrm{mg} / \mathrm{kg})$ was administered subcutaneously $24 \mathrm{~h}$ before the LPS/HI injury.

The diffusion tensor imaging (DTI) data were analyzed using tractbased spatial statistics (TBSS) algorithms implemented in FSL [FMRIB (Functional MRI of the Brain) Software Library; http://fsl.fmrib.ox.ac. uk/fsl/fslwiki/] and modified for rat (Smith et al., 2004; Madelin and Regatte, 2013). Briefly, the fractional anisotropy (FA) maps were created by fitting a tensor model to the raw diffusion data using FDT (Functional MRI of the Brain Diffusion Toolbox) and then brain extracted with BET (FMRIB Brain Extract Tool; Smith, 2002). All subjects' FA data were aligned into a common space using the nonlinear image registration tool FNIRT (FMRIB Linear Image Registration Tool), which uses a $b$-spline representation of the registration warp field (Rueckert et al., 1999). A mean FA image was created and thinned to create a mean FA skeleton that represented the centers of all tracts common to the group. Each subject's aligned FA data and mean, radial, and axial diffusivity changes were then projected onto this skeleton, and the resulting data were fed into voxelwise cross-subject statistics, including corrections for multiple comparisons.

Statistical analysis. All values were expressed as mean \pm SD or SEM (when $n \geq 10$ ). Quantitative data were compared using two-sample (unpaired) $t$ test assuming equal variance or one-way ANOVA, followed by Newman-Keuls multiple comparisons for post hoc test. $p$ values of $<0.05$ were considered significant.

$\leftarrow$

(Figure legend continued.) binding affinity to the S1PR2 isoform (Mandala et al., 2002). $\boldsymbol{F}$, Neither pFTY720 nor S1P prevented LPS-induced IL-23 mRNA in SM826 microglial cells (shown are the mean and SD of three experiments). $\mathbf{G}$, Immunoblot analysis of the effect of S1P and TatNBD peptide $(5,20 \mu \mathrm{M})$ on LPS $(5 \mathrm{ng} / \mathrm{ml})$-induced NF- $\kappa$ B signaling activation in SM826 microglial cells. The Tat-NBD peptide showed dose-dependent attenuation of $\mid \kappa B \alpha$ degradation in the cytosol and nuclear accumulation of NF- $\kappa$ B/RelA at 30 min after LPS-exposure, whereas S1P lacked this effect (shown are the typical result in 3 experiments). $\boldsymbol{H}$, Eight hours exposure to S1P produced dose-dependent reduction of the S1PR1 mRNA level in SM826 cells (shown are the mean and SD in three experiments). UN, Untouched.

\section{Results}

Inflammation-sensitized $\mathrm{HI}$ induces systemic $\mathrm{T}_{\mathrm{H}}$ 17-ike cells and focal invasion of $\mathrm{CD} 43^{+}$leukocytes through the choroid plexus

To test whether intrauterine infection accelerates the development of $\mathrm{T}_{\mathrm{H}} 17$ lymphocytes, we first compared the expression of IL-23R mRNA, a marker of $\mathrm{T}_{\mathrm{H}} 17$ cells, in aliquots of CBMCs isolated from late preterm neonates (32-36 gestational weeks) with and without histological chorioamnionitis. This analysis showed a $292 \%$ increase of $I L-23 R$ mRNA in those with severe chorioamnionitis (fetal vasculitis; Fig. $1 A$ ). Next we used the well characterized LPS-sensitized HI brain injury model in P7 rats to compare the effects of low-dose LPS $(0.3 \mathrm{mg} / \mathrm{kg}$, i.p.), HI, and combined LPS/HI on the expression of $I L-23 R$ mRNA in the PBMCs (Eklind et al., 2005). We found that LPS-sensitized HI injury caused a significant increase of $I L-23 R$ mRNA expression at $4 \mathrm{~h}$ after insult, whereas pure-HI and low-dose LPS challenge lacked this effect (Fig. 1B).

However, the expression of $I L-17 A$ mRNA was not significantly elevated in either human or rodent mononuclear cells, suggesting that the IL-23R ${ }^{+}$mononuclear cells are early-stage $\mathrm{T}_{\mathrm{H}} 17$ cells but not fully matured $\mathrm{T}_{\mathrm{H}} 17$ effector cells (Korn et al., 2009). Consistent with this idea, flow cytometry analysis showed a comparable $\mathrm{CD} 4{ }^{+} / \mathrm{CD}^{+} \mathrm{T}$-cell ratio in the blood mononuclear cells among untouched and low-dose LPS-, HI-, or LPS/HIinjured rat pups and a small increase of $\mathrm{CD} 4^{+} \mathrm{IL}^{+} 17 \mathrm{~A}^{+}$ lymphocytes $(4.92 \%)$ at $16 \mathrm{~h}$ recovery after the dual LPS/HI insult (Fig. 1C). These results suggest that LPS-sensitized neonatal HI injury does not induce a systemic surge of mature $\mathrm{T}_{\mathrm{H}} 17$ effector cells.

Next we tested the possibility of early influx of lymphocytes into neonatal brains after various stimuli by immunostaining with the anti-CD43 (leukosialin) antibody, a commonly used pan-T-cell marker that is expressed to a lesser degree in other leukocytes (Ward et al., 2006). We found that the choroid plexus in untouched rats displays a high level of CD43 immunoreactivity among cell junctions, likely as part of the dense glycocalyx oligosaccharide domain in the brain-interstitial fluid interface because of its $>100$ extracellular sialic acid residues (Fig. 1D; Debbage, 1996; Ostberg et al., 1998). The anti-CD43 immunoreactivity in the choroid plexus was reduced after exposure to low-dose LPS and further decreased after pure- and LPS-sensitized HI injury at $4 \mathrm{~h}$ recovery (Fig. 1D). Contrary to the normal ribbon-like CD43 immunoreactivity, many $\mathrm{CD} 43^{+}$cells were detected in the ipsilateral choroid plexus and scattered into the nearby white matter (WM) after the dual LPS/HI injury (Fig. 1D). In the contralateral choroid plexus after LPS/HI injury, fewer CD $43^{+}$cells were present, and they were imbedded in the preserved CD $43^{+}$strip. These results suggest that HI brain injury downregulates CD43 immunoreactivity in the choroid plexus, and the dual LPS/HI insult causes early influx of $\mathrm{CD} 43^{+}$leukocytes into neonatal brains.

\section{Systemic FTY720 administration prevents early infiltration of} $\mathrm{CD} 3^{+}$leukocytes

Next we examined the effects of FTY720 administration $(1 \mu \mathrm{g} / \mathrm{g}$, i.p.) after LPS/HI insult in P7 rat pups. Consistent with its ability to prevent lymphocyte egress from lymph nodes (Mandala et al., 2002), FTY720 blocked the increase of $I L-23 R$ mRNAs in the rat blood mononuclear cells at $4 \mathrm{~h}$ recovery (Fig. $1 B$ ). Moreover, FTY720 preferentially reduced CD $4{ }^{+}$T-cells and produced nearcomplete depletion of systemic CD4 ${ }^{+} \mathrm{IL}^{-17 \mathrm{~A}^{+}}$T-lymphocytes at $16 \mathrm{~h}$ after LPS/HI injury (Fig. 1C). Finally, the FTY720 treatment preserved the ribbon-like CD43 immunoreactivity in the 
A
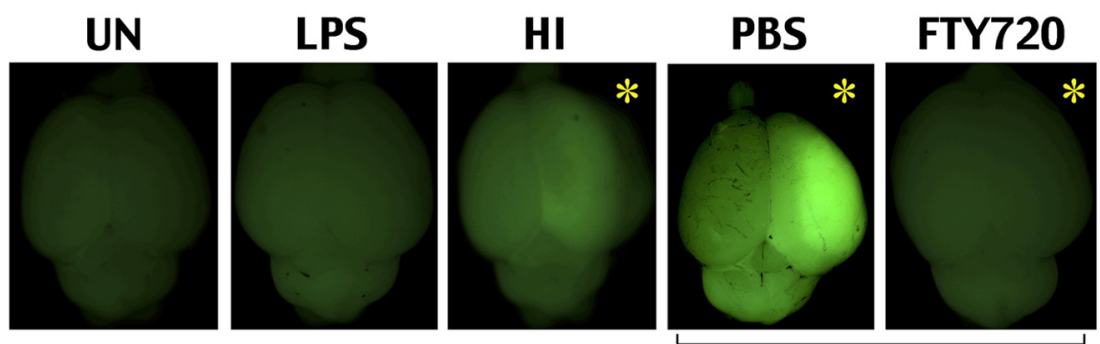

LPS/HI
B

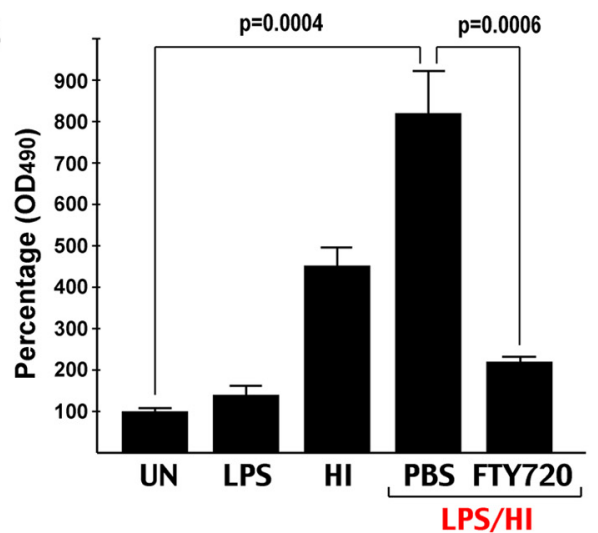

C

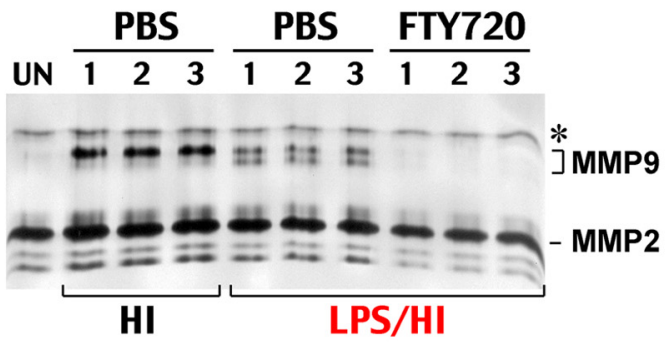

E

D

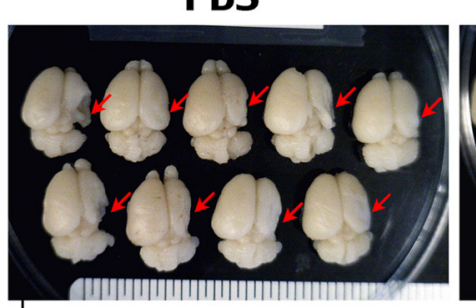

$\operatorname{FTY720}(1 \mu \mathrm{g} / \mathrm{g})$

$\mathbf{F}$

LPS/HI (80')

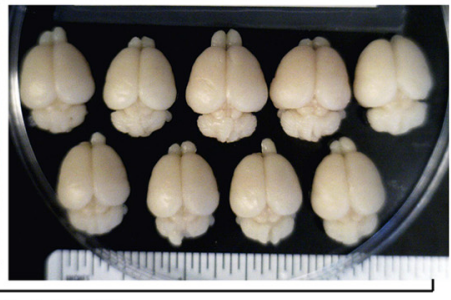

\section{(}
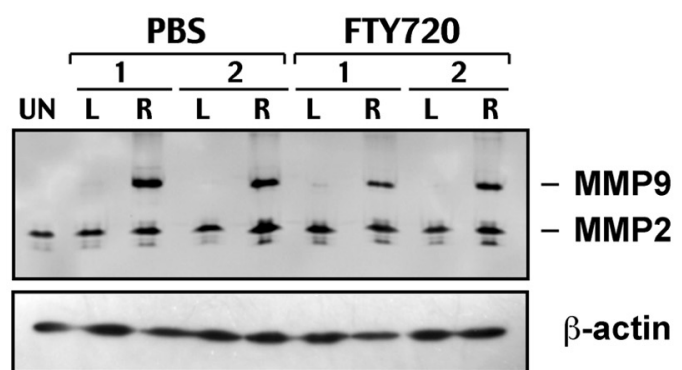

$\beta$-actin

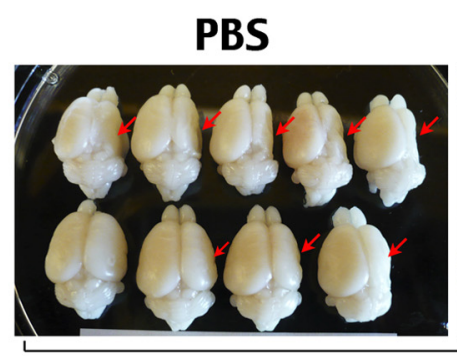

FTY720 $(1 \mu \mathrm{g} / \mathrm{g})$

HI

HI (90')

G
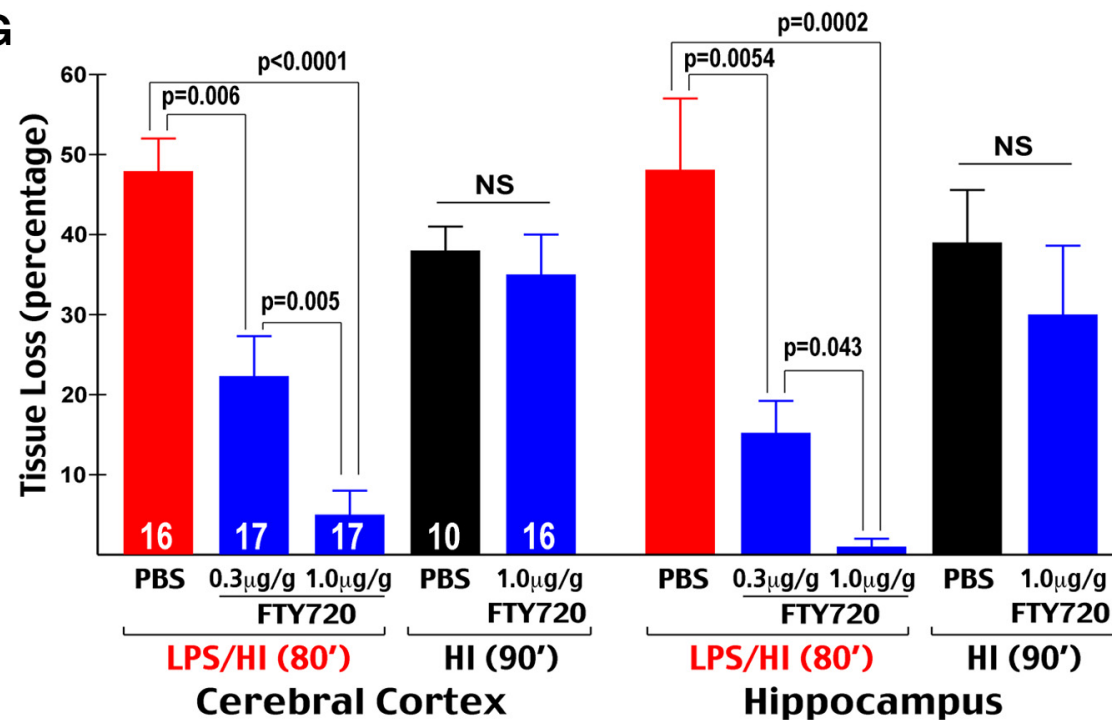

Hippocampus

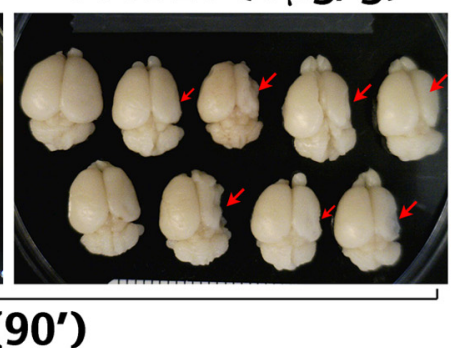

Figure 5. FTY720 markedly reduces LPS/HI brain injury but is ineffective against pure HI injury. Because 80 min pure-HI insult caused little brain damage (Yang et al., 2013a), we used a longer duration of pure-HI $(90 \mathrm{~min})$ to compare with the combined LPS/HI $(80 \mathrm{~min})$ insult. $A$, Representative brain photographs of P8 rats that were treated by the indicated condition $24 \mathrm{~h}$ earlier and received an intraperitoneal injection of $\mathrm{NaF}$ at $2 \mathrm{~h}$ before transcardial perfusion; the residual $\mathrm{NaF}$ fluorescence in the $\mathrm{HI}$-injured hemisphere (asterisks) indicates $\mathrm{BBB}$ damage and increased permeability. B, Quantification of NaF fluorescence in the LPS-, HI-, or LPS/HI-treated hemisphere compared with untouched (UN) brains. LPS/HI injury markedly induced BBB permeability, which was significantly reduced by the FTY720 treatment ( $n=3$ for untouched, 4 for LPS-alone, and 5 for HI, LPS/HI-PBS, and LPS/HI-FTY720 groups). C, MMP zymogram of the ipsilateral rat cortical hemisphere collected at $24 \mathrm{~h}$ after the indicated treatment. Shown are three typical samples in each condition. Asterisk indicates nonspecific band. Note the induction (Figure legend continues.) 
ipsilateral choroid plexus and mitigated the influx of $\mathrm{CD} 43^{+}$ leukocytes at $4 \mathrm{~h}$ after the dual LPS/HI injury (Fig. 1D).

\section{$\mathrm{CD} 3^{+}$leukocytes enter neonatal brains in two distinct sequences after LPS/HI injury}

In experimental autoimmune encephalomyelitis (EAE), $T_{H} 17$ cells enter the CNS initially through the choroid plexus and secondarily in the leptomeningeal space after substantial brain damage and opening of the BBB (Ransohoff et al., 2003; Kebir et al., 2007; Reboldi et al., 2009). Similarly, at $4 \mathrm{~h}$ after the LPS/HI injury, we only detected $\mathrm{CD} 43^{+}$leukocytes in the choroid plexus and the nearby subcortical WM, in which they were mixed with $\mathrm{Iba}^{+}$amoeboid microglial cells (Fig. $2 A, B$ ). In contrast, very few $\mathrm{CD} 43^{+}$cells were present in the leptomeningeal space at this early time point (Fig. $2 D, E$ ). Post-LPS/HI administration of FTY720 led to the absence of CD43 ${ }^{+}$cells in the subcortical WM (Fig. 2C,F). The FTY720 treatment also greatly reduced the LPS/ HI-triggered nuclear NF- $\kappa \mathrm{B}$ activity and degradation of cytosolic $\mathrm{I} \kappa \mathrm{B} \alpha$ at $4 \mathrm{~h}$ recovery (Fig. $2 M, N$ ), which are among the earliest biochemical signs for neuroinflammatory response in this model (Yang et al., 2013a,b).

At $18-24 \mathrm{~h}$ after LPS/HI injury, there were more evidences of neuroinflammation (see the description of Fig. 3). Meanwhile, the leptomeningeal space became dilated and filled with CD $43^{+}$ leukocytes in the ipsilateral, but not the contralateral, hemisphere or after the FTY720 treatment (Fig. 2G-I). Similarly, the LPS/HIinjured cerebral cortex contained a large number of $\mathrm{CD} 43^{+}$leukocytes and numerous round, $\mathrm{Iba}^{+}$phagocytic microglia/ macrophages, which were both absent in the contralateral hemisphere and after the FTY720 treatment (Fig. $2 J-L$ ). These observations suggest two spatiotemporally distinct routes of leukocyte influx in LPS/HI-injured neonatal brains, which were both greatly attenuated by post-injury administration of FTY720.

\section{FTY720 attenuates neuroinflammation and reduces $\mathrm{CD} 4{ }^{+}$ IL-17A ${ }^{+}$lymphocytes after LPS/HI injury}

Next we used flow cytometry to compare the percentage of $\mathrm{CD} 4^{+}$ IL-17A ${ }^{+}$T-cells at $24 \mathrm{~h}$ after LPS, HI (90 min), or LPS plus 80 min $\mathrm{HI}$ brain injury. We chose a longer duration of pure-HI insult, because $80 \mathrm{~min} \mathrm{HI}$ produced milder brain damage and little neuroinflammation (Yang et al., 2013a). We wanted to compare the $\mathrm{T}_{\mathrm{H}} 17 / \mathrm{IL}-17$ activity under pure-HI (90 $\mathrm{min}$ ) and LPS/HI $(80 \mathrm{~min}$ ) insults that produce similar levels of brain injury (for effects of brain atrophy, see Fig. 5). This analysis showed $<3 \%$ of $\mathrm{CD}^{+}{ }^{+} \mathrm{IL}^{-17 \mathrm{~A}^{+}}$lymphocytes among $\mathrm{CD}^{+}{ }^{+} \mathrm{T}$-cells in untouched, LPS-challenged, and pure-HI injured brains. The dual LPS/HI insult led to a significant increase to $21 \%$ of $\mathrm{CD} 4{ }^{+}$IL$17 \mathrm{~A}^{+} \mathrm{T}$-cells, which was reduced to $12 \%$ by FTY720 treatment (Fig. $3 A$ ).

\section{$\leftarrow$}

(Figure legend continued.) of MMP9 by HI or LPS/HI insult, additional processing of MMP9 in LPS/HI insult, and the absence of MMP9 induction in FTY720-treated animals. $D$, Representative brains of the LPS/HI-injured and saline or FTY720 $(1 \mu \mathrm{g} / \mathrm{g}$ body $\times 2)$-treated rat pups at $7 \mathrm{~d}$ recovery. Red arrows indicate brain atrophy. $\boldsymbol{E}, \mathrm{MMP}$ zymogram of rat brains subjected to $\mathrm{HI}$ injury and the saline versus FTY720 treatment at $24 \mathrm{~h}$ recovery. Shown are two representative samples in each treatment. The FTY720 therapy failed to prevent HI-induced MMP9 activation in the ipsilateral (right, R) cortical hemisphere. L, Left. $\boldsymbol{F}$, Typical brains of HI-injured rat pups that received either saline or FTY720 $(1 \mu \mathrm{g} / \mathrm{g}$ body $\times 2)$ treatment at $7 \mathrm{~d}$ recovery. G, Quantification of tissue loss in the cerebral cortex, hippocampus, and striatum after the indicated injury and treatment at $7 \mathrm{~d}$ recovery ( $n=10-17$ in each group as indicated). The FTY720 treatment conferred dose-dependent reduction of LPS/HI-induced tissue loss in all regions but resulted in a similar extent of brain atrophy after pure-HI injury.
We then used RT-PCR to compare the mRNA levels of RORc, IL-23R, IL-17A, IL-22 (all markers of $\mathrm{T}_{\mathrm{H}} 17$ cells), Tbx21/T-bet (a marker of $\mathrm{T}_{\mathrm{H}} 1$ and mixed $\mathrm{T}_{\mathrm{H}} 1 / \mathrm{T}_{\mathrm{H}} 17$ cells), IFN $\gamma\left(\right.$ a $\mathrm{T}_{\mathrm{H}} 1$ cell marker), and Gata3 and $I L-13$ (markers of $\mathrm{T}_{\mathrm{H}} 2$ cells) between pure-HI injury and LPS/HI injury with or without the FTY720 treatment. The analysis showed that combined LPS/HI insult has a greater propensity than pure-HI injury to induce $\mathrm{T}_{\mathrm{H}} 17$ markers, which were markedly reduced by the FTY720 treatment $(p<$ 0.05 difference in the induction of $R O R c, I L-23 R$, and $I L-17 A$ mRNA between HI and LPS/HI injury and the amelioration by FTY720). In contrast, the enhancement of $\mathrm{T}_{\mathrm{H}} 1$ and $\mathrm{T}_{\mathrm{H}} 2$ markers by the LPS/HI injury was either insignificant (in Tbx21, Gata3, and IL-13 mRNA) or reversed by the pure-HI insult (in IFN $\gamma$ ). Furthermore, the FTY720 treatment only significantly attenuated the induction of Tbx21 mRNA but not the other $\mathrm{T}_{\mathrm{H}} 1$ and $\mathrm{T}_{\mathrm{H}} 2$ markers (Fig. 3B). Together, the flow cytometry and RT-PCR findings suggest that combined LPS/HI injury induces, whereas FTY720 attenuates, the $\mathrm{T}_{\mathrm{H}}$ 17/IL-17A-mediated immune response in neonatal brains.

In addition, the FTY720 treatment markedly reduced the expression of MCP1 protein and TSPO, which are both indicators of neuroinflammation and microglial activation (Martín et al., 2010; Yang et al., 2013a) at 18-24 h after LPS/HI injury (Fig. $3 C-E)$. In contrast, the FTY720 treatment failed to prevent the LPS/HI-triggered rise of plasma MCP1, supporting its CNScentric effects (Fig. 3E).

\section{FTY720 lacks direct inhibitory effects on microglia}

Our results suggest that FTY720 primarily blocks brain influx of leukocytes to prevent LPS/HI-induced neuroinflammation. An alternative explanation is that FTY720 might directly inhibit microglia activation, as has been suggested (Noda et al., 2013). To distinguish between these two scenarios, we tested the effects of FTY720 on the MCP1 induction after cerebral ventricle injection of LPS, a paradigm of direct microglial activation (Yang et al., 2013a). This experiment showed that the FTY720 treatment was unable to prevent direct LPS-induced MCP1 induction (Fig. 4A). Next, we performed intracerebroventricular injection of LPS in bitransgenic CX3CR1-GFP; CCR2-RFP mice, in which the microglia and circulating monocytes are marked by the green and red fluorescence protein, respectively (Jung et al., 2000; Saederup et al., 2010). We found that, in unchallenged mice, the brains were essentially devoid of monocytes, and the microglial processes were excluded from the hippocampal pyramidal cell layer. In contrast, after intracerebroventricular LPS injection, both saline- and FTY720-treated mice showed intrusion of hypertrophic microglia processes in the hippocampal pyramidal cell layer and a massive influx of monocytes, as expected by the increase of brain MCP1 level (Fig. 4B). Likewise, in immortalized microglial cells, low-dose LPS $(5 \mathrm{ng} / \mathrm{ml}$ ) readily induced the expression of iNOS, COX 2 , and proinflammatory IL- $1 \beta$ or IL- 6 cytokines despite the presence of up to $10 \mu \mathrm{M}$ phosphorylated FTY720 (pFTY720; Fig. 4B,C).

These in vivo and in vitro results argued against direct inhibition of microglia by FTY720, which prompted us to examine the expression of S1PR isoforms in neonatal rat microglia. The RTqPCR analysis showed that, although S1PR1 is the most abundant isoform in microglia, there was also a high expression level of S1PR2, an isoform to which pFTY720 lacks binding affinity (Mandala et al., 2002), which could render (p)FTY720 unable to prevent microglia activation directly (Fig. 4E). Thus, we also compared the effects of pFTY720 and S1P on LPS-induced ex- 

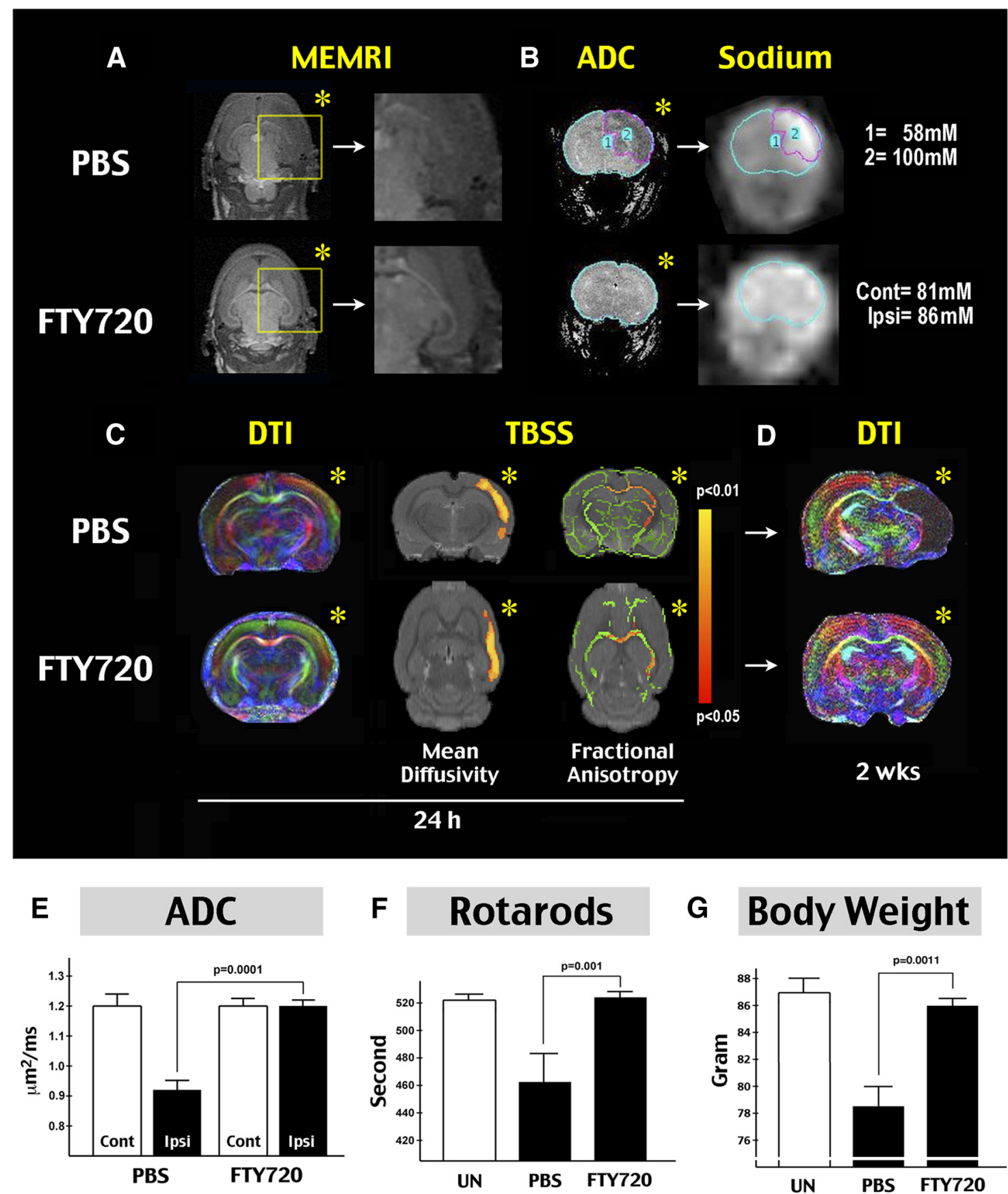

Figure 6. FTY720 protects WM and motor development after neonatal LPS/HI injury. A, MEMRI comparison at $24 \mathrm{~h}$ recovery. Note the disappearance of cytoarchitectural distinctions in the ipsilateral hemisphere (asterisk) in saline-treated, but not FTY720-treated, rats ( $n=4-5$ for each group). $B$, Comparison of ADC at $24 \mathrm{~h}$ after LPS/HI. Note the reduction of ADC signals in the ipsilateral hemisphere in saline-treated animals (asterisk). Sodium MRI acquisition and quantification showed spatial correlation between increased sodium concentration and reduced ADC signal. The LPS/HI injury also caused shifting of sodium toward the ipsilateral hemisphere. C, Representative in vivo DTI image of saline- and FTY720-treated animals at $24 \mathrm{~h}$ recovery of LPS/HI injury. The TBSS detected regions with $p<0.05$ difference in mean diffusivity (in gray matter) and FA (WM) between saline-treated $(n=5)$ and FTY720-treated $(n=4)$ animals at $24 \mathrm{~h}$ after LPS/HI injury. $D$, Representative in vivo diffusion tensor image of saline- and FTY720-treated rat pups at $14 \mathrm{~d}$ recovery. $\boldsymbol{E}$, Quantification showed significant preservation of ADC signals in the cerebral cortex of FTY720-treated rat pups $(n=8)$ when compared with those receiving the saline treatment $(n=9) . F$, Comparison of the latency to fall (seconds) on rotarods in untouched (UN), LPS/HI-injured and saline- or FTY720-treated rat pups at $24 \mathrm{~d}$ of age ( $n=3$ for untouched, 8 each for saline- and FTY720-treated animals). G, Comparison of the body weight of untouched, LPS/HI-injured, and salineor FTY720-treated rats pups at $24 \mathrm{~d}$ of age ( $n=3$ for untouched, 8 for saline- or FTY720-treated animals). Cont, Contralateral; Ipsi, ipsilateral.

pression of $I L-23$ (a key factor for $\mathrm{T}_{\mathrm{H}} 17$ cell differentiation), TNF $\alpha$, and iNOS mRNA (Ghoreschi et al., 2010). This analysis showed that neither pFTY720 nor S1P (up to $10 \mu \mathrm{M}$ ) suppressed microglial activation directly (Fig. $4 F$ and data not shown). Finally, we compared the effects of S1P and Tat-Nemo Binding Domain (NBD), an anti-NF- $\kappa$ B peptide (May et al., 2000; Yang et al., 2013b), on the intracellular signaling responses to LPS in immortalized microglial cells. We found that Tat-NBD provided dose-dependent attenuation of LPS-induced degradation of cytosolic I $\kappa \mathrm{B} \alpha$ and accumulation of nuclear NF- $\kappa \mathrm{B} / \mathrm{RelA}$, whereas up to $20 \mu \mathrm{M} \mathrm{S1P} \mathrm{exerted} \mathrm{no} \mathrm{opposing} \mathrm{effects} \mathrm{(Fig.} 4 G$ ). In contrast, the S1P treatment showed dose-dependent reduction of S1PR1 mRNA as negative feedback of the signaling pathway (Brinkmann et al., 2010; Fig. 4H). 


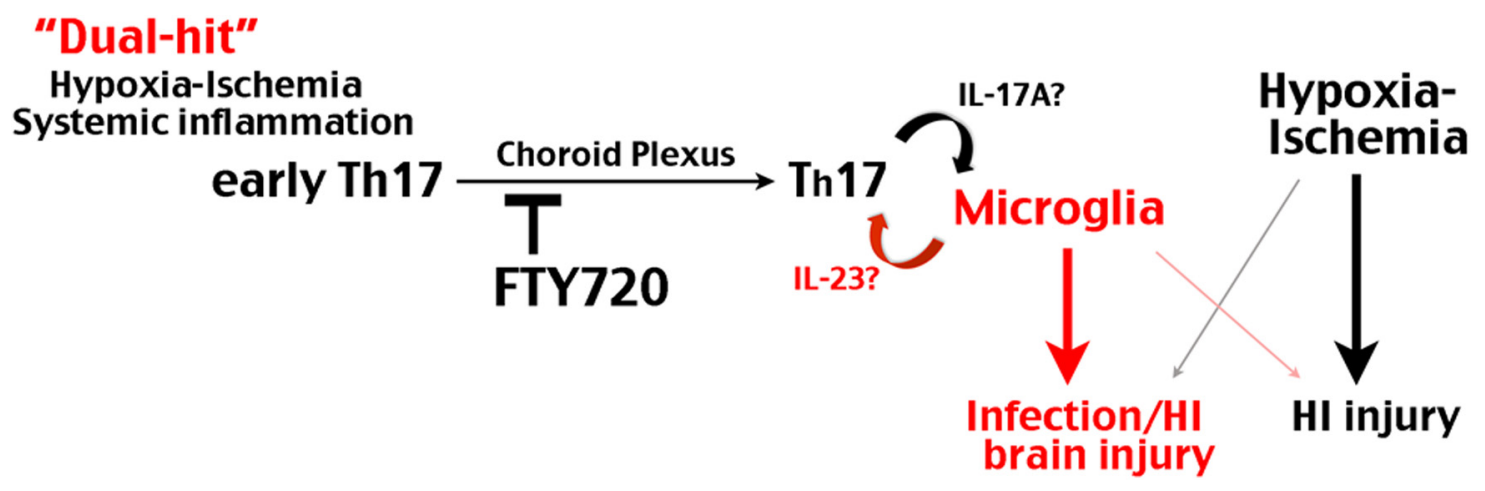

Figure 7. Divergent pathogenic pathways in pure versus inflammation-sensitized HI injury in neonatal brains. Our results suggest that the combined insult of fetal/peripheral inflammation and $H$ induces early-stage $\mathrm{T}_{H} 17$ cells to enter neonatal brains through the choroid plexus to amplify microglial activation, which plays a preferential role in infection-sensitized over pure-HI brain injury. Our results also indicate that the benefits of FTY720 against LPS-sensitized HI injury mainly derive from blocking the brain influx of early-onset T-cells through the choroid plexus. Whether microglia feedback to promote $\mathrm{T}_{\mathrm{H}} 17$ cell maturation and the cytokines involved in the reciprocal activation is yet to determined.

Together, these in vivo and in vitro results suggest that FTY720 (and the active metabolite pFTY720) lack direct inhibition on microglia. Thus, the suppression of microglial activation in neonatal LPS/HI injury is more likely mediated through another population of target cells.

FTY720 selectively prevents LPS-sensitized, but not pure-HI, brain injury

Another possibility that we considered is whether (p)FTY720 exerts direct neuroprotection, although the majority of past reports disfavored this scenario (Liesz et al., 2011; Wei et al. 2011; Deogracias et al., 2012). Nevertheless, we compared the effects of FTY720 on pure-HI (90 min) and LPS-sensitized HI (80 min) insult, reasoning that FTY720 should oppose both insults if its benefits are derived primarily from neuronal protection. Of note, because $80 \mathrm{~min}$ pure-HI insult caused little brain damage (Yang et al., 2013a), we used a longer duration of pure-HI (90 min) in this experiment.

We found that FTY720 markedly attenuated LPS/HItriggered $\mathrm{BBB}$ damage, as shown by reduced $\mathrm{NaF}$ extravasation and diminished MMP9 activity in the ipsilateral hemisphere (Fig. $5 A-C)$. This experiment also showed greater BBB damage and more advanced MMP9 processing by the LPS/HI insults. Moreover, FTY720 provided dose-dependent reduction of brain atrophy, salvaging $>90 \%$ of LPS/HI-induced tissue loss in the hippocampus and the cerebral cortex if the treatment was started within $30 \mathrm{~min}$ after injury (Fig. 5D-G). In contrast, the acute FTY720 treatment failed to prevent MMP9 activation or brain atrophy after pure-HI injury (Fig. $5 E-G$ ).

Together, the observed distinct effects by FTY720 in these two forms of $\mathrm{HI}$ injury suggest that it disrupts a unique mechanism in endotoxin/LPS-sensitized neonatal HI brain injury.

\section{FTY720 reduces acute brain atrophy and protects normal} development of motor functions

Finally, we used MRI and behavioral testing to assess both acute and long-term effects of FTY720 treatment in LPS/HI injury. MEMRI showed that FTY720 preserved brain cytoarchitectural distinctions in the ipsilateral hemisphere, which became obfuscated in saline-treated animals at $24 \mathrm{~h}$ after LPS/HI (Fig. 6A). Moreover, although saline-treated pups showed reduction of ADC coinciding with increased sodium concentration in the ipsilateral hemisphere at $24 \mathrm{~h}$ recovery (Madelin and Regatte, 2013), the FTY720 treatment mitigated both responses (Fig. 6B$E)$. In addition, in vivo DTI and TBSS analysis identified areas of $p<0.05$ reduction in mean diffusivity (in gray matter) or FA (in $\mathrm{WM}$ ) at $24 \mathrm{~h}$ recovery in the ipsilateral hemisphere of salinetreated, but not FTY720-treated, animals (Smith et al., 2006; Fig. $6 C)$. Two weeks later, the TBSS-identified at-risk gray matter and WM became atrophic or distorted in saline-treated rat pups (Fig. 6D). Finally, the FTY720-treated rats showed near-normal gain in body weight and the latency in rotarods by $24 \mathrm{~d}$ of age, far better than the outcomes in saline-treated siblings (Fig. 6F, G). Together, these results suggest that the FTY720 treatment not only reduces acute brain atrophy but also protects normal growth and motor development after neonatal LPS/HI brain injury.

\section{Discussion}

Growing evidence indicates that perinatal inflammation exacerbates $\mathrm{HI}$ and excitotoxic lesions, causing greater brain damage in neonates (Dommergues et al., 2000; Dammann et al., 2002; Hagberg et al., 2012; Degos et al., 2013). Consequently, preclinical and clinical studies both indicate that inflammation-sensitized HI brain injury is less responsive to therapeutic hypothermia than pure-HI injury in neonates (Wintermark et al., 2010; Osredkar et al., 2014). Hence, better understanding the unique mechanisms of inflammation-sensitized HI brain injury is needed to develop more effective therapies. In this study, we provide evidences that inflammation-sensitized HI triggers early onset of $\mathrm{T}_{\mathrm{H}}$ 17/IL-17-mediated immune responses to damage neonatal brains, which can be ameliorated by blocking lymphocyte trafficking with FTY720, an oral medicine that is in clinical use for treating multiple sclerosis (Brinkmann et al., 2010). Figure 7 depicts the deduced mechanisms of inflammation-sensitized neonatal HI brain injury based on our results and those in previous studies. This model emphasizes divergent pathological mechanisms between pure- and inflammation-sensitized neonatal HI brain injuries. It also supports the proposal that microglial activation is a pivotal step in inflammation/HI brain injury (Khwaja and Volpe, 2008).

In support of divergent pathological mechanisms, past studies have shown that, in LPS-sensitized HI injury, the brain innate immune responses and NF- $\kappa \mathrm{B}$ activity are triggered as early as $4 \mathrm{~h}$ recovery (Yang et al., 2013a,b). In contrast, microglia are activated secondary to tissue damage in a delayed manner after pure-HI insult (Hagberg et al., 2012). Furthermore, gene deletion of $M y D 88$ or pharmacological inhibition of the NF- $\kappa \mathrm{B}$ pathway markedly reduces LPS-sensitized neonatal HI brain injury but confers little to no protection against pure-HI injury (Wang et al., 2009; Yang et al., 2013a). Our results further suggest that the dual 
hit of systemic inflammation and HI uniquely induces the influx of early-stage $\mathrm{T}_{\mathrm{H}} 17$ cells to coordinate neuroinflammation, which can be successfully blocked by the FTY720 treatment.

FTY720 is a potent agonist of the S1PRs with multiple actions, but its most robust effect is to sequester lymphocytes in lymph nodes and block their trafficking to the target organs (Mandala et al., 2002; Brinkmann et al., 2010). Consistent with this mechanism, we showed that post-LPS/HI administration of FTY720 markedly reduced systemic $\mathrm{CD} 4{ }^{+} \mathrm{T}$-cells, rapid influx of CD43 ${ }^{+}$ leukocytes in the choroid plexus, acute activation of the NF- $\kappa \mathrm{B}$ signaling pathway, and accumulation of CD4 ${ }^{+} \mathrm{IL}^{-17 \mathrm{~A}^{+}} \mathrm{T}$-cells in the neonatal brain. We also showed that FTY720 (and its active metabolite pFTY720) neither opposes pure-HI brain injury nor directly inhibits microglial activation. These paradoxical "negative" findings are in agreement with recent reports showing that FTY720 neither reduces acute brain infarction nor exerts direct neuroprotection, although it reduces the influx of lymphocytes in cerebral ischemia (Liesz et al., 2011; Wei et al., 2011). Furthermore, genetic ablation of IL-17 fails to reduce acute cerebral ischemic injury (Shichita et al., 2009). Thus, the most logical explanation of our results is that FTY720 blocks early influx of lymphocytes in the neonatal brain, which is a unique and important pathogenic mechanism in inflammation-sensitized HI injury but absent in pure-HI injury. This interpretation is consistent with the study showing delayed influx of T-cells at days to weeks after neonatal pure-HI injury (Winerdal et al., 2012). One limitation of our study in rats is the lack of suitable histochemical reagents to define the early-entry CD $43^{+}$leukocytes. Future studies in mice are needed to fully characterize their immunological properties.

Noticeably, our results show that the combined inflammation/HI injury does not induce a large increase of systemic $\mathrm{T}_{\mathrm{H}} 17$ cells at 16-24 h recovery, whereas significant increase of CD4 ${ }^{+}$ IL-17A ${ }^{+}$T-cells are only present in neonate brains. This restricted distribution pattern suggests that full maturation of $\mathrm{T}_{\mathrm{H}} 17$ cells may require stimulation by activated microglia in the brain. This scenario is in accord with a previous study showing that, during LPS stimulation, neonatal T cells upregulate a functional IL-23R to become early-stage $\mathrm{T}_{\mathrm{H}} 17$ cells and respond to IL-23 secreted by tissue-specific dendritic cells to become effector $\mathrm{T}_{\mathrm{H}} 17$ lymphocytes (Vanden Eijnden et al., 2006). Similarly, we detected rapid induction of $I L-23 R$ mRNAs in the PBMCs and expression of $I L-23$ by LPS-stimulated microglia. Together, these results suggest that activated microglia or monocytes in LPS/HIinjured neonatal brains may secrete IL-23 to promote full maturation of $\mathrm{T}_{\mathrm{H}} 17$ effector cells (Fig. 7). Future studies are warranted to determine the activation cytokines between $\mathrm{T}_{\mathrm{H}} 17$ lymphocytes and microglia/monocytes, which may be additional therapeutic targets of inflammation-sensitized HI brain injury in newborns.

The proposed mechanism also raises unanswered questions. First, because full maturation of $\mathrm{T}_{\mathrm{H}} 17$ cells is not a prerequisite for entering neonatal brains according to our hypothesis, the dual LPS/HI-injured brain must have a unique mechanism to recruit systemic early-stage $\mathrm{T}_{\mathrm{H}} 17$ cells. Our results show that leukocytes enter LPS/HI-injured neonatal brains first in the choroid plexus and, 16-24 h later, via the leptomeningeal space. This spatiotemporal sequence of cell influx is similar to the order of T-cell infiltration in EAE and in line with the findings of acute T-cell accumulation in the choroid plexus after peripheral immune activation (Ransohoff et al., 2003; Petito and Adkins, 2005; Reboldi et al., 2009). Second, the observed rapid decline of anti-CD43 immunoreactivity in the choroid plexus after LPS/HI injury is intriguing, in view of the effects by CD43 in limiting T-cell hom- ing attributable to its glycosylation-associated negative charge in the extracellular domain (Ostberg et al., 1998; Stockton et al., 1998). The rapid decline of CD43 immunoreactivity in the choroid plexus (which may signify protein degradation or shedding of sialic acid residues) may remove the barrier and allow CD $43^{+}$ $\mathrm{T}$-cells to interact with its ligands, such as $\mathrm{P}$ - and E-selectin, in the choroid plexus for transmigration into the brain (Kivisäkk et al., 2003; Matsumoto et al., 2005). This scenario is in line with a recent study showing that systemic inflammation may lead to disturbances in choroid plexus barrier function to facilitate the influx of immune cells (Stridh et al., 2013). Future studies using T-cell live-imaging and manipulation of CD43 glycosylation are warranted to test this hypothesis.

Finally, our results suggest that FTY720 may be a promising treatment of inflammation-sensitized HI brain injury in term or near-term neonates. This application is important because $40-$ $50 \%$ of infants treated with hypothermia still die or suffer significant neurological disabilities, and cooling in the presence of inflammation appears less effective (Wintermark et al., 2010; Higgins et al., 2011; Osredkar et al., 2014). Although FTY720 is an immune modulator, it does not promote post-stroke bacterial infections (Pfeilschifter et al., 2011), and our study demonstrates that it does not impair neonatal development or worsen pure-HI brain injury. Thus, FTY720 may be a useful adjuvant to therapeutic hypothermia when prenatal infection of asphyxiated infants is suspected.

In conclusion, the present study suggests a novel pathological mechanism that can be used to control inflammation-sensitized HI brain injury in newborns. Future studies are warranted to ascertain the association of $\mathrm{T}_{\mathrm{H}} 17$ cells with infection-sensitized brain injury by flow cytometry and the safety of administering FTY720 in human neonates for potential clinical application.

\section{References}

Bettelli E, Carrier Y, Gao W, Korn T, Strom TB, Oukka M, Weiner HL, Kuchroo VK (2006) Reciprocal developmental pathways for the generation of pathogenic effector TH17 and regulatory T cells. Nature 441:235238. CrossRef Medline

Brinkmann V, Billich A, Baumruker T, Heining P, Schmouder R, Francis G, Aradhye S, Burtin P (2010) Fingolimod (FTY720): discovery and development of an oral drug to treat multiple sclerosis. Nat Rev Drug Discov 9:883-897. CrossRef Medline

Dammann O, Kuban KC, Leviton A (2002) Perinatal infection, fetal inflammatory response, white matter damage, and cognitive limitations in children born preterm. Ment Retard Dev Disabil Res Rev 8:46-50. CrossRef Medline

Debbage PL (1996) A systematic histochemical investigation in mammals of the dense glycocalyx glycosylations common to all cells bordering the interstitial fluid compartment of the brain. Acta Histochemica 98:9-28. CrossRef Medline

Degos V, Peineau S, Nijboer C, Kaindl AM, Sigaut S, Favrais G, Plaisant F, Teissier N, Gouadon E, Lombet A, Saliba E, Collingridge GL, Maze M, Nicoletti F, Heijnen C, Mantz J, Kavelaars A, Gressens P (2013) G protein-coupled receptor kinase 2 and group I metabotropic glutamate receptors mediate inflammation-induced sensitization to excitotoxic neurodegeneration. Ann Neurol 73:667-678. CrossRef Medline

Deogracias R, Yazdani M, Dekkers MP, Guy J, Ionescu MC, Vogt KE, Barde YA (2012) Fingolimod, a sphingosine-1 phosphate receptor modulator, increases BDNF levels and improves symptoms of a mouse model of Rett syndrome. Proc Natl Acad Sci U S A 109:14230-14235. CrossRef Medline

Dommergues MA, Patkai J, Renauld JC, Evrard P, Gressens P (2000) Proinflammatory cytokines and interleukin-9 exacerbate excitotoxic lesions of the newborn murine neopallium. Ann Neurol 47:54-63. CrossRef Medline

Duggan PJ, Maalouf EF, Watts TL, Sullivan MH, Counsell SJ, Allsop J, AlNakib L, Rutherford MA, Battin M, Roberts I, Edwards AD (2001) Intrauterine T-cell activation and increased proinflammatory cytokine 
concentrations in preterm infants with cerebral lesions. Lancet 358:16991700. CrossRef Medline

Eklind S, Mallard C, Arvidsson P, Hagberg H (2005) Lipopolysaccharide induces both a primary and a secondary phase of sensitization in the developing rat brain. Pediatr Res 58:112-116. CrossRef Medline

Ghoreschi K, Laurence A, Yang XP, Tato CM, McGeachy MJ, Konkel JE, Ramos HL, Wei L, Davidson TS, Bouladoux N, Grainger JR, Chen Q, Kanno Y, Watford WT, Sun HW, Eberl G, Shevach EM, Belkaid Y, Cua DJ, Chen W, O'Shea JJ (2010) Generation of pathogenic T(H)17 cells in the absence of TGF-beta signalling. Nature 467:967-971. CrossRef Medline

Hagberg H, Gressens P, Mallard C (2012) Inflammation during fetal and neonatal life: implications for neurologic and neuropsychiatric disease in children and adults. Ann Neurol 71:444-457. CrossRef Medline

Higgins RD, Raju T, Edwards AD, Azzopardi DV, Bose CL, Clark RH, Ferriero DM, Guillet R, Gunn AJ, Hagberg H, Hirtz D, Inder TE, Jacobs SE, Jenkins D, Juul S, Laptook AR, Lucey JF, Maze M, Palmer C, Papile L, Pfister RH, Robertson NJ, Rutherford M, Shankaran S, Silverstein FS, Soll RF, Thoresen M, Walsh WF (2011) Hypothermia and other treatment options for neonatal encephalopathy: an executive summary of the Eunice Kennedy Shriver NICHD workshop. J Pediatr 159:851-858.e1. CrossRef Medline

Jung S, Aliberti J, Graemmel P, Sunshine MJ, Kreutzberg GW, Sher A, Littman DR (2000) Analysis of fractalkine receptor CX(3)CR1 function by targeted deletion and green fluorescent protein reporter gene insertion. Mol Cell Biol 20:4106-4114. CrossRef Medline

Kallapur SG, Presicce P, Senthamaraikannan P, Alvarez M, Tarantal AF, Miller LM, Jobe AH, Chougnet CA (2013) Intra-amniotic IL-1beta induces fetal inflammation in rhesus monkeys and alters the regulatory $\mathrm{T}$ cell/IL-17 balance. J Immunol 191:1102-1109. CrossRef Medline

Kebir H, Kreymborg K, Ifergan I, Dodelet-Devillers A, Cayrol R, Bernard M, Giuliani F, Arbour N, Becher B, Prat A (2007) Human TH17 lymphocytes promote blood-brain barrier disruption and central nervous system inflammation. Nat Med 13:1173-1175. CrossRef Medline

Khwaja O, Volpe JJ (2008) Pathogenesis of cerebral white matter injury of prematurity. Arch Dis Child Fetal Neonatal Ed 93:F153-F161. Medline

Kivisäkk P, Mahad DJ, Callahan MK, Trebst C, Tucky B, Wei T, Wu L, Baekkevold ES, Lassmann H, Staugaitis SM, Campbell JJ, Ransohoff RM (2003) Human cerebrospinal fluid central memory CD4+ T cells: evidence for trafficking through choroid plexus and meninges via P-selectin. Proc Natl Acad Sci U S A 100:8389-8394. CrossRef Medline

Korn T, Bettelli E, Oukka M, Kuchroo VK (2009) IL-17 and Th17 cells. Annu Rev Immunol 27:485-517. CrossRef Medline

Lehnardt S, Massillon L, Follett P, Jensen FE, Ratan R, Rosenberg PA, Volpe JJ, Vartanian T (2003) Activation of innate immunity in the CNS triggers neurodegeneration through a Toll-like receptor 4-dependent pathway. Proc Natl Acad Sci U S A 100:8514-8519. CrossRef Medline

Leviton A, Dammann O, Durum SK (2005) The adaptive immune response in neonatal cerebral white matter damage. Ann Neurol 58:821-828. CrossRef Medline

Liesz A, Sun L, Zhou W, Schwarting S, Mracsko E, Zorn M, Bauer H, Sommer C, Veltkamp R (2011) FTY720 reduces post-ischemic brain lymphocyte influx but does not improve outcome in permanent murine cerebral ischemia. PLoS One 6:e21312. CrossRef Medline

Madelin G, Regatte RR (2013) Biomedical applications of sodium MRI in vivo. J Magn Reson Imaging 38:511-529. CrossRef Medline

Mandala S, Hajdu R, Bergstrom J, Quackenbush E, Xie J, Milligan J, Thornton R, Shei GJ, Card D, Keohane C, Rosenbach M, Hale J, Lynch CL, Rupprecht K, Parsons W, Rosen H (2002) Alteration of lymphocyte trafficking by sphingosine-1-phosphate receptor agonists. Science 296:346-349. CrossRef Medline

Martín A, Boisgard R, Thézé B, Van Camp N, Kuhnast B, Damont A, Kassiou M, Dollé F, Tavitian B (2010) Evaluation of the PBR/TSPO radioligand [(18)F]DPA-714 in a rat model of focal cerebral ischemia. J Cereb Blood Flow Metab 30:230-241. CrossRef Medline

Matsumoto M, Atarashi K, Umemoto E, Furukawa Y, Shigeta A, Miyasaka M, Hirata T (2005) CD43 functions as a ligand for E-Selectin on activated T cells. J Immunol 175:8042-8050. CrossRef Medline

May MJ, D'Acquisto F, Madge LA, Glöckner J, Pober JS, Ghosh S (2000) Selective inhibition of NF-kappaB activation by a peptide that blocks the interaction of NEMO with the IkappaB kinase complex. Science 289: 1550-1554. CrossRef Medline
Noda H, Takeuchi H, Mizuno T, Suzumura A (2013) Fingolimod phosphate promotes the neuroprotective effects of microglia. J Neuroimmunol 256:13-18. CrossRef Medline

Osredkar D, Thoresen M, Maes E, Flatebø T, Elstad M, Sabir H (2014) Hypothermia is not neuroprotective after infection-sensitized neonatal hypoxic-ischemic brain injury. Resuscitation 85:567-572. CrossRef Medline

Ostberg JR, Barth RK, Frelinger JG (1998) The Roman god Janus: a paradigm for the function of CD43. Immunol Today 19:546-550. CrossRef Medline

Petito CK, Adkins B (2005) Choroid plexus selectively accumulates T-lymphocytes in normal controls and after peripheral immune activation. J Neuroimmunol 162:19-27. CrossRef Medline

Pfeilschifter W, Czech-Zechmeister B, Sujak M, Foerch C, Wichelhaus TA, Pfeilschifter J (2011) Treatment with the immunomodulator FTY720 does not promote spontaneous bacterial infections after experimental stroke in mice. Exp Transl Stroke Med 3:2. CrossRef Medline

Pino PA, Cardona AE (2011) Isolation of brain and spinal cord mononuclear cells using percoll gradients. J Vis Exp pii:2348. CrossRef Medline

Ransohoff RM, Kivisäkk P, Kidd G (2003) Three or more routes for leukocyte migration into the central nervous system. Nat Rev Immunol 3:569581. CrossRef Medline

Reboldi A, Coisne C, Baumjohann D, Benvenuto F, Bottinelli D, Lira S, Uccelli A, Lanzavecchia A, Engelhardt B, Sallusto F (2009) C-C chemokine receptor 6-regulated entry of TH-17 cells into the CNS through the choroid plexus is required for the initiation of EAE. Nat Immunol 10:514523. CrossRef Medline

Rueckert D, Sonoda LI, Hayes C, Hill DL, Leach MO, Hawkes DJ (1999) Nonrigid registration using free-form deformations: application to breast MR images. IEEE Trans Med Imaging 18:712-721. CrossRef Medline

Saederup N, Cardona AE, Croft K, Mizutani M, Cotleur AC, Tsou CL, Ransohoff RM, Charo IF (2010) Selective chemokine receptor usage by central nervous system myeloid cells in CCR2-red fluorescent protein knock-in mice. PLoS One 5:e13693. CrossRef Medline

Sharma AA, Jen R, Butler A, Lavoie PM (2012) The developing human preterm neonatal immune system: a case for more research in this area. Clin Immunol 145:61-68. CrossRef Medline

Shereen A, Nemkul N, Yang D, Adhami F, Dunn RS, Hazen ML, Nakafuku M, Ning G, Lindquist DM, Kuan CY (2011) Ex vivo diffusion tensor imaging and neuropathological correlation in a murine model of hypoxia-ischemia-induced thrombotic stroke. J Cereb Blood Flow Metab 31:1155-1169. CrossRef Medline

Shichita T, Sugiyama Y, Ooboshi H, Sugimori H, Nakagawa R, Takada I, Iwaki T, Okada Y, Iida M, Cua DJ, Iwakura Y, Yoshimura A (2009) Pivotal role of cerebral interleukin-17-producing gammadeltaT cells in the delayed phase of ischemic brain injury. Nat Med 15:946-950. CrossRef Medline

Smith SM (2002) Fast robust automated brain extraction. Hum Brain Mapp 17:143-155. CrossRef Medline

Smith SM, Jenkinson M, Woolrich MW, Beckmann CF, Behrens TE, Johansen-Berg H, Bannister PR, De Luca M, Drobnjak I, Flitney DE, Niazy RK, Saunders J, Vickers J, Zhang Y, De Stefano N, Brady JM, Matthews PM (2004) Advances in functional and structural MR image analysis and implementation as FSL. Neuroimage 23 [Suppl 1]:S208-S219. Medline

Smith SM, Jenkinson M, Johansen-Berg H, Rueckert D, Nichols TE, Mackay CE, Watkins KE, Ciccarelli O, Cader MZ, Matthews PM, Behrens TE (2006) Tract-based spatial statistics: voxelwise analysis of multi-subject diffusion data. Neuroimage 31:1487-1505. CrossRef Medline

Stockton BM, Cheng G, Manjunath N, Ardman B, von Andrian UH (1998) Negative regulation of $\mathrm{T}$ cell homing by CD43. Immunity 8:373-381. CrossRef Medline

Stridh L, Ek CJ, Wang X, Nilsson H, Mallard C (2013) Regulation of Tolllike receptors in the choroid plexus in the immature brain after systemic inflammatory stimuli. Transl Stroke Res 4:220-227. CrossRef Medline

Vanden Eijnden S, Goriely S, De Wit D, Goldman M, Willems F (2006) Preferential production of the IL-12(p40)/IL-23(p19) heterodimer by dendritic cells from human newborns. Eur J Immunol 36:21-26. CrossRef Medline

Wang X, Stridh L, Li W, Dean J, Elmgren A, Gan L, Eriksson K, Hagberg H, Mallard C (2009) Lipopolysaccharide sensitizes neonatal hypoxic- 
ischemic brain injury in a MyD88-dependent manner. J Immunol 183: 7471-7477. CrossRef Medline

Ward JM, Erexson CR, Faucette LJ, Foley JF, Dijkstra C, Cattoretti G (2006) Immunohistochemical markers for the rodent immune system. Toxicol Pathol 34:616-630. CrossRef Medline

Wei Y, Yemisci M, Kim HH, Yung LM, Shin HK, Hwang SK, Guo S, Qin T, Alsharif N, Brinkmann V, Liao JK, Lo EH, Waeber C (2011) Fingolimod provides long-term protection in rodent models of cerebral ischemia. Ann Neurol 69:119-129. CrossRef Medline

Wetterling F, Tabbert M, Junge S, Gallagher L, Macrae IM, Fagan AJ (2010) A double-tuned $1 \mathrm{H} / 23 \mathrm{Na}$ dual resonator system for tissue sodium concentration measurements in the rat brain via Na-MRI. Phys Med Biol 55:7681-7695. CrossRef Medline

Winerdal M, Winerdal ME, Kinn J, Urmaliya V, Winqvist O, Adén U (2012) Long lasting local and systemic inflammation after cerebral hypoxic ischemia in newborn mice. PLoS One 7:e36422. CrossRef Medline

Wintermark P, Boyd T, Gregas MC, Labrecque M, Hansen A (2010) Placen- tal pathology in asphyxiated newborns meeting the criteria for therapeutic hypothermia. Am J Obstet Gynecol 203:579.e1-579.e9. CrossRef Medline

Wu YW (2002) Systematic review of chorioamnionitis and cerebral palsy. Ment Retard Dev Disabil Res Rev 8:25-29. CrossRef Medline

Wu YW, Escobar GJ, Grether JK, Croen LA, Greene JD, Newman TB (2003) Chorioamnionitis and cerebral palsy in term and near-term infants. JAMA 290:2677-2684. CrossRef Medline

Yang D, Sun YY, Nemkul N, Baumann JM, Shereen A, Dunn RS, Wills-Karp M, Lawrence DA, Lindquist DM, Kuan CY (2013a) Plasminogen activator inhibitor-1 mitigates brain injury in a rat model of infection-sensitized neonatal hypoxia-ischemia. Cereb Cortex 23:1218-1229. CrossRef Medline

Yang D, Sun YY, Lin X, Baumann JM, Dunn RS, Lindquist DM, Kuan CY (2013b) Intranasal delivery of cell-penetrating anti-NF-kappaB peptides (Tat-NBD) alleviates infection-sensitized hypoxic-ischemic brain injury. Exp Neurol 247:447-455. CrossRef Medline 